Mitteilungen aus der Akademie für praktische Medizin in Köln.

\title{
Beiträge zur Anatomie und Pathologie der quer- gestreiften Muskelfaser. Experimentelle Studien zur Lehre von der ischämischen Muskellähmung und Muskelkontraktur.
}

Von Dr. Fritz Kroh, Sekundärarzt der chirurgischen Abteilung des Augustahospitals Köln (Chefarzt: Geh.-Rat Prof. Dr. Bardenheuer).

I. Teil.

Beiträge zur Anatomie und Pathologie der quergestreiften Muskelfaser.

Als seinerzeit mein verehrter Chef, Herr Geh. Rat Bardenheuer, vor Ausgabe seiner Arbeit über „Die Entstehung und Behandlung der ischämischen Muskelkontraktur und Gangrän“, mit der Anregung an mich herantrat, auf experimentellem Wege der Ontogenese der ischämischen Muskelveränderung nachzuspüren, glaubte ich, in dem Versuche, die bis dato vorliegenden, in der Arbeit Hildebrands „Die Lehre von den ischämischen Muskellähmungen ,und Kontrakturen“ zusammengestellten Beobachtungen weiter auszubauen, derselben gerecht werden $\mathrm{zu}$ können. Bei weiterer Vertiefung in die feineren degenerativen Vorgänge der Muskelfaser, deren Studium eine genauere Berücksichtigung der normal-anatomischen Struktur und des physiologischen Verhaltens derselben zur selbstverständlichen Voraussetzung machte, entwickelte sich ein scheinbar abseits führender Weg, der aber begangen werden mußte, um das Ziel zu erreichen, von dem aus etappenförmig sich neue interessante Pfade eröffneten; - dem auf diesem Gebiete noch unerfahrenen Leser glaube ich mit Wiedergabe meiner Eindrücke eine Anregung zu geben, der Kenner mag dieselben sachlich beurteilen. -- Dann erst schritt ich zur Kritik der bislang geübten Versuchstechnik, 
die praktisch ausgiebig nachgeprüft wurde, und gelangte schließ. lich auf einen Weg, der vielleicht einem rationellen Aufschlusse über die Ätiologie und über den Verlauf der ischämischen Muskellähmung und Muskelkontraktur näherkommt.

Die quergestreifte Muskelfaser, ein strukturell außerordentlich kompliziertes Gebilde, ist bekanntlich ein Komplex von Zellen, die ihrem Bau, ihrer Zusammengehörigkeit und Bestimmung nach nur entwicklungsgeschichtlich oder - bei Untersuchung der einzelnen Faserregenerationsstadien - eingehend studiert und exakter definiert werden können; in der ausgebildeten Muskelfaser dürften dieselben wohl schwerlich noch zur Darstellung kommen. - Es gelang mir wohl einige Male, einzelne leicht granulierte, miteinander in Kontakt stehende Protoplasmafortsätze tinktionell zu fixieren; die Frage, ob diese, wie es den Anschein haben konnte, in Wirklichkeit Ausläufer von Muskelzellen waren, mußte ich offen lassen.

Erschwert wird der Einblick in die normale Struktur der Muskelfaser durch mancherlei Reaktionen, in denen dieselbe ihre besondere Reizbarkeit mechanischen oder chemischen Altera. tionen gegenüber äußert; die Kenntnis dieser Reaktionen ist unerläßlich, sie fordert äußerste Vorsicht in der Präparatentnahme, und die Kritik der Umstände, unter denen dieselbe statthatte, ob in vivo, ob vor, ob nach Eintritt der Muskelstarre, auch mahnt sie zur Orientierung über die Lebensbedingungen, unter denen der zu untersuchende Muskel bei Lebzeiten gestanden. Für die Untersuchung der Faser ist es aus noch zu besprechenden gewichtigen Gründen sicherlich nicht gleichgültig, ob das lebendfrische Präparat in physiologischer NaCl-Lösung suspendiert oder sofort in Formalin fixiert und studiert wurde.

Die Muskelfaser, deren Längenmaß stark variiert - als Höchstmaß notierte ich bei Untersuchung des Kaninchenmuskels $2,8 \mathrm{~cm}$-, ist also ein Komplex von Zellen, die, als solche schließlich nicht mehr zu identifizieren, völlig in der Bildung der kontraktilen Substanz aufgehen, die Zellkerne bleiben in ursprünglicher Form erhalten und maßgebend für die Erhaltung und Entwicklung des Faserkörpers. Innerhalb eines Sarkolemmschlauches, d.i. eine wasserklare, zarte Haut, die die Muskelfaser als Ganzes umschließt, also in der kontraktilen Substanz 
herrscht nicht nur ein einziger bestimmter Kerntyp vor; bei genauerem Zusehen erkennt man mancherlei Formen; es ist nicht unwahrscheinlich, daß, wie die Form, so auch die funktionelle Tätigkeit der Kerne verschieden ist. - Man findet nun langgestreckte, leicht granulierte Kerne, die fast ausnahmslos dem Sarkolemmschlauche angelagert sind. Andere numerisch diese überragend, sind mehr rundlich bis oval und bläschenförmig mit deutlichen - gewöhnlich zwei - Kernkörperchen, sie liegen in der kontraktilen Substanz verstreut.

Die Kernfiguren, die man hie und da außerdem noch zu Gesicht bekommt, darf man m. E. der bisher beschriebenen Spezies wohl angliedern. Man könnte zur Erklärung der Formverschiedenheit einmal ungleichmäßige Schnittführung verantwortlich machen, oder annehmen, daß diese Formen den alten Typ darstellen in dem Zustande der Anpassung an die jeweilige Kontraktionsphase der Muskelfaser. In diesem Sinne liefern die dem Sarkolemmschlauche angelagerten Kerne wohl am ehesten instruktive Bilder: So sieht man dieselben in Schnitten eines Muskelpräparates, das im Kontraktionszustande fixiert wurde, auf einen beträchtlichen Teil ihrer Länge reduziert, im Querdurchmesser entsprechend verbreitert; in den Schnittbildern eines anderen Präparates, das einer verbrannten Extremität entnommen und gleichfalls noch im Zustande extremer Verkürzung zur Untersuchung kam, drängen sich dieselben durch den Sarkolemmschlauch derart vor, daß derselbe wie von Perlen übersät erscheint. - Für die Verschiedenheit der einzelnen Kernindividuen besonders charakteristisch ist das Verhalten derselben im Stadium der Faserregeneration. Aus den Regenerationsformen lassen sich immer wieder zwei Haupttypen herauslesen, das sind Zellen mit den oben näher geschilderten ovalären und solche mit langgestreckten Kernen; dieselben sind untereinander weiterhin noch durch die Art der Vermehrung unterschieden, zeigen im ersten Falle mitotische und amitotische, im letzten nur direkte Teilung.

Bei Beschreibung der Muskelzellen halten wir uns an die Bilder, die wir bei dem Studium der Muskeldegeneration und -regeneration festhielten; wir glauben, da $B$ mit der Untersuchung der einzelnen Regenerationsphasen der anatomischen Klarstellung dieser Zellgebilde ebenso exakt gedient ist, wie mit einschlägigen 
embryologischen Studien, prinzipielle Unterschiede dürften auf keinen Fall bestehen. Ohne hier schon auf die Degenerationsvorgänge bestimmter eingehen $\mathrm{z} u$ wollen, sei nur hervorgehoben, daß, wirkte auf die Muskelfasern bei exakt gebliebener, wenn auch im Einzelfalle mitunter stark reduzierter Gewebsernährung, irgendein tiefer greifendes Reizmoment (ein mechanischer, chemischer Insult, künstliche Unterbrechung der Nervenleitung) neben den typischen Degenerationsbildern die Regenerationsformen in oft geradezu prodigiöser Weise auftraten und im großen und ganzen, im Gegensatze zu der Variabilität des Degenerationszustandes ihrer Umgebung einen mehr einheitlichen Entwicklungsgang zeigten. Ihren Endzweck - selbständige oder gemeinsame Bildung einer Muskelfaser - erreichen freilich nicht alle, vielmehr ist oft genug festzustellen, daß das Maximum auf niederer oder höherer Entwicklungsstufe wieder zugrunde geht. In der ersten Entwicklungsphase präsentieren alle denselben Typ. Man greife die Zellindividuen beispielsweise vor, während oder nach Ausbildung des Muskelzellenschlauches (Waldeyer) heraus: sie beginnen stets - soweit als tinktionell feststellbar als anfänglich nackte Kerne, die früher oder später von einer kleineren oder größeren Protoplasmamenge umsäumt werden, schließlich zu einer rundlichen, polygonalen oder spindelförmigen Zelle auswachsen. Der erste und zweite Typ bildet wohl die Hauptmasse der Zellen des Muskelzellenschlauches; die Spindelform findet sich auffallend häufig dicht unter der Sarkolemmhülle und ist durch einen mehr oder weniger gestreckten Kern ausgezeichnet, dieser wieder durch direkte Teilung charakterisiert; sie ist aller Wahrscheinlichkeit nach an der Regeneration des Sarkolemmschlauches, der im übrigen erstaunliche Resistenz zeigt, beteiligt. Es gibt noch eine andere Spindelform, die ich in den Schnittpräparaten von Extremitäten, deren Nervenbahnen künstlich unterbrochen waren, besonders häufig antraf; dieselbe ist aber von der soeben beschriebenen durch einen rund-ovalen Kern, der wieder dem der vollentwickelten Muskelfaser ähnelt, charakteristisch unterschieden.

Die eigentliche Entwicklung der Muskelfaser erscheint in der Hauptsache an ein weiteres Auswachsen und die Kernvermehrung der letztgeschilderten Spindelzelle gebunden. Die Kerne 
stehen kettenförmig geordnet. Ungefähr synchron mit größerer Wachstumstendenz entwickelt sich eine zarte fibrilläre Struktur, die scheinbar immer zuerst in der Peripherie des Protoplasmamantels auftritt, dann erst axialwärts zur Ausbildung kommt; diese jungen Fibrillen nehmen die Hämatoxylinfärbung viel intensiver an, als die der fertigen Muskelfaser.

Entsprechend der Progredienz der Fibrillenzeichnung rücken die Zellkerne nun schneller oder langsamer vom Zentrum des in diesem Entwicklungsstadium schon als - primitive - Muskelfaser zu deutenden Zellenbildes mehr peripherwärts, erst nach bzw. mit Abschluß der Fibrillenzeichnung erscheint die Querstreifung und der die junge Faser schärfer konturierende Sarkolemmüberzug.

Bei dieser Regenerationsform handelt es sich — und das sei ausdrücklich betont - um Spindelzellen, die nach Trennung der Kontinuität des Sarkolemmschlauches gleichsam ausgesprengt, aus dem Zellverbande des Muskelzellenschlauches gelöst, isoliert zur Entwicklung kamen; Wert lege ich auf die besondere Feststellung, daß jeglicher Kontakt auch mit den langkernigen Spindelzellen auszuschließen war - als Erklärung für die Vermutung, daß3 die Entwicklung der Sarkolemmhülle nicht immer nur an die Präexistenz einer besonderen Zellform, wie sie eben geschildert, gebunden ist, daß dieselbe sich vielmehr auch im Einzelfalle zwanglos als Umwandlungsprodukt der Außenschicht des Protoplasmamantels definieren läßt.

Das Endprodukt der Weiterentwicklung dieses Regenerationstyps ist einmal eine einheitliche Muskelfaser. In einigen Fällen konnte ich aber auch die Beobachtung machen, daß in einem bestimmten Entwicklungsstadium gerade in diesem bestimmten Typ wieder eine lebhafte Kernvermehrung einsetzte mit nebenschichtiger Kettenanordnung, worauf dann eine Aufspaltung in der Richtung der Längsachse der Faser erfolgte, und jede Kernreihe mit dem zugehörigen schmalen Protoplasmasaume als selbständiges Faserindividuum scheinbar zur Weiterentwicklung kam. - Anders das Regenerationsbild innerhalb des intakt gebliebenen Sarkolemmschlauches. Wir wiesen oben auf die verschiedene Gestaltung der Zellen des Muskelzellenschlauches hin; diese Zellen - die Spindelzellen, die gewöhnlich sarkolemm- 
wärts gedrängt werden, ausgeschlossen - fallen größtenteils anscheinend dem Expansionsbestreben der jungen Faserspindel zum Opfer: gegen Ende der dritten Regenerationswoche sieht man zahlreiche Kernpyknosen, nur einige wenige Kerne persistieren, diese scheinbar auch nur für eine gewisse Zeit; über die Funktion und speziell den späteren Verbleib der letzteren konnte ich trotz aufmerksamer Untersuchung keine Aufklärung erhalten. Item: durch einfachen Kontakt der Faserspindeln entwickelt sich innerhalb der durch das Sarcolemma vorgeschriebenen Grenzen aus der degenerierten die neue Muskelfaser. Ungeklärt bleibt die eigentliche Bedeutung der dem Sarkolemmschlauche neu angelagerten Spindelzellen. - Wenn die Annahme, daß derselbe unter gegebenen Verhältnissen dieser Zellform seine Entstehung verdankt, zu Recht besteht, dann wäre auch für den konkreten Fall die Vermutung, daß dieselbe durch ihre Lebenstätigkeit, vielleicht schon allein durch einfache Anlagerung, dem alten Sarkolemmschlauche bei dem Versuche der Anpassung an die Qualität und Quantität des neuen Faserinhaltes eine gewisse mechanische Kräftigung biete, billig.

Von dem tatsächlich physiologischen Werte dieser Spindelzellen überzeugt man sich bei dem Studium der Regenerationsvorgänge von Muskelfasern, deren Sarcolemma während oder nach Ausbildung des Zellschlauches irgendwelche Kontinuitätstrennung erlitt; in solchen Fällen ließ sich hier und da ein direkter genetischer Zusammenhang der Spindelzelle und Sarkolemmdecke - gleichgültig, ob letztere dann als Umwandlungsoder Ausscheidungsprodukt aufzufassen - mit zweifelloser Sicherheit nachweisen. Schminke, der die Bildung des Sarkolemms bei dem Laubfrosche und bei der Kröte untersuchte, läßt dasselbe vom Bindegewebe abstammen. Pielsticker hält diese Annahme immerhin für möglich, vermutet dann aber, daß es sich um ein durch den engen Konnex mit der kontraktilen Substanz, durch die „Symbiose" verändertes Bindegewebe handele. Die. Möglichkeit dieses Entstehungsmodus gebe ich zu, die Vollgültigkeit dieser Auffassung bestreite ich, eben unter dem Eindrucke unserer Untersuchungsergebnisse: oft genug sahen wir Regenerationsvorgänge an Sarkolemmschläuchen, die neben Schädigung ihres Inhaltes selbst Kontinuitätstrennungen aufwiesen, 
dabei aber in keinem nennenswerten Kontakte mit den nächstbenachbarten Zellen standen, vielmehr durch Gewebsödem und dadurch bedingte Dehiszenz einzelner zellulärer und nicht zellulärer Gewebsteile häufig völlig isoliert waren.

Thoma, dessen ausführlichen Studien über degenerative Muskelveränderungen wir wertvolle Aufschlüsse verdanken, kommt bei Untersuchung der der Muskelverletzung sich anschließenden Regenerationsvorgänge zu Ergebnissen, die nicht unwesentlich von unseren Beobachtungen abweichen. Dieser Unterschied ist mehr weniger prinzipiell, deshalb von geringerer Bedeutung die Betonung, daß Thoma die Regenerationsvorgänge in der Muskulatur fast ausschließlich nach Vorausschickung einer Kontinuitätstrennung nur -des Faserinhaltes, weniger unter Berücksichtigung anderer Insulte bzw. Reizeffekte studiert hätte -, weil nämlich unsere Untersuchungen teilweise sich auch unter derselben Voraussetzung bewegten, trotzdem zu gegenteiligen Ergebnissen kamen. Der Schluß, zu dem $\mathrm{T}$ hom a kommt, basiert, wie beifolgendes Resümee zeigt, mehr auf psycho-mechanischen Erwägungen. Danach führt die Kontinuitätstrennung des Sarkolemmainhaltes zu einem Zuströmen von Sarkoplasma und Muskelkernen aus dem unverletzten Teile der Muskelfaser, bei welchem, Zuströmen der gestörte Gewebsdruck und die Spannung der Primitivfibrillen die Vis a tergo abgeben. Unter Mitwirkung der durch die lokale Störung erzeugten Kreislaufsanomalien erfolgt sodann eine Neubildung von protoplasmatischer Muskelsubstanz, welche sich weiterhin in Primitivfibrillen und Sarkoplasma scheidet und den Defekt ausfüllt. Vorübergehend tritt dabei auf dem Wege der Mitose eine Kernvermehrung ein, die später wieder durch einen pyknotischen Kernschwund gehoben wird. Die infolge der Kontinuitätstrennung des Sarkolemmainhaltes erfolgte Anhäufung der Muskelkerne in dem Verletzungsgebiete wird schlieblich durch eine Kernrückwanderung wieder ausgeglichen, für welche die bei wiederkehrender Funktion sich einstellenden, in unregelmäßigen Perioden wiederkehrenden Spannungen der Primitivfibrillen die erforderliche Vis a tergo abgeben. Damit erst ist der endgültige $A b s c h l u B$ der Regenerationsvorgänge erreicht und das ursprüngliche Verhalten der Muskelfaser vollkommen wieder hergestellt. Und gerade, weil das unterscheidende Moment je nach Beweiskraft auch völlig bindend sein muß für schließlich alle Regenerationsformen, die in dem eigentlich strittigen Punkte: Zellwucherung - keinen prinzipiellen Unterschied zeigen, wäre es auch verfehlt, darüber zu diskutieren, daß Thoma sich in der Hauptsache ausschließlich mit dem Studium der aus dem unverletzten Sarkolemmainhalt aussprossenden Muskelknospen beschäftigt hätte - das objektiv nicht viel Neues bringen konnte - und weniger mit den Regenerationsvorgängen der Muskelfaser, die unter der 
Totalwirkung eines Degenerationsprozesses stand. Wohl wird über die Regenerationsvorgänge der Muskelfasern, in denen sich nach Ablösung der von Thoma so bezeichneten und noch einmal zu besprechenden "maximal kontrahierten Wülste" - ein ausgedehnter diskoider Zerfall der angrenzenden Teile des unverletzten Sarkolemmainhaltes eingestellt hatte, berichtet. Die diskoiden Massen verlieren ebenso wie die Kontraktionswülste ihre Doppelbrechung und werden hyalin, hinzu kommt noch eine starke Quellung; der Effekt dieser regressiven Umwandlung ist: eine nahezu homogene Substanz, in der außer den von undifferenziertem Protoplasma umsäumten Muskelkernen zahlreiche phagocytäre Leukocyten suspendiert sind; nach Resorption und Verflüssigung der hyalinen Massen verschwinden die Leukocyten, die freigewordenen Muskelkörperchen, schlechtweg als "Sarkolyten" bezeichnet, persistieren, verschmelzen und leiten somit als Sarkoblasten die Neuentwicklung der alten Faser ein.

Wir konnten bei Untersuchung der die eigentliche Regeneration einleitenden posttraumatischen Faserveränderung den Angaben Thomas nur beipflichten. Betrachten wir den letzten wie den ersten Regenerationsmodus: beide gelten und lassen sich immer wieder nachweisen; beiden gemeinsam ist der einleitende Umwandlungsprozeß; die posttraumatischen Kontraktionseffekte: die Wülste und die denselben ähnlichen diskoiden Massen verlieren ihre Doppelbrechung und gehen in hyaline Substanz über; letztere quillt und verflüssigt. Bis zur Beobachtung dieses Entwicklungsstadiums stehe ich in Übereinstimmung mit Thoma; aus der verschiedenen Beantwortung der Frage, $\mathrm{ob}$ in diesen frühen Stadien des Regenerationsvorganges eine Teilung der Muskelkerne statthat, ergibt sich die Divergenz der Beurteilung der weiteren Regenerationserscheinungen. Nach Thoma enthält der Muskelzellenschlauch (Waldeyer) Sarkolyten und Leukocyten; aus einer Verschmelzung der isolierten Muskelkörperchen resultiert nach Eliminierung der Leukocyten die neue Muskelfaser. Von einer Vermehrung und konsekutiven elektiven Vereinigung spezifischer Zellindividuen - der Ausgangspunkt unserer früheren Besprechung - ist nichts erwähnt.

Thoma stellte bei Untersuchung der Muskelsprossenbildung eine mäßige Vermehrung der Kerne des erhaltengebliebenen, an das Verletzungsgebiet grenzenden Sarkolemminhaltes fest; in vielen Fällen führe die Kernvermehrung zur Bildung von Kernhaufen, die wieder zumeist in den axialen Teilen der Muskelfaser 
liegen und wandern sollen: sie dringen in die Muskelsprossen ein, liegen später in denselben, um schließlich in den Muskelfaserbrücken nachweisbar zu werden. - Man könnte diese zeitlich wechselnde Lage der Kernhaufen auf eine von dem Faserstumpfe ausgehende progrediente Kernwucherung zurückführen, der ein gleichfalls progredienter, aber nur partieller Kernschwund wieder unmittelbar folgt. Thoma hält eine ähnliche Annahme deshalb für wenig wahrscheinlich, weil man einmal nicht in der Lage sei, mitotische oder amitotische Kernteilung im Gebiete der Kernhaufen zu finden und damit den direkten Beweis für eine Neubildung von Muskelkernen zu führen und dann auch Kernpyknosen nur in beschränktem Maße feststellen könne. - Es kann kein bloßer Zufall sein, daß es uns so überaus häufig gelang, die oben beschriebenen Kernteilungsvorgänge in dem einen wie dem anderen Regenerationsmodus und den eben erwähnten Stadien sowie dann wieder partiellen pyknotischen Zerfall zu fixieren. Zur Darstellung der einzelnen Entwicklungsphasen benutzten wir mit Erfolg die Hämatoxylinfärbung (Delafield).

Unter dem Eindrucke dieser tatsächlichen Vermehrung spezifischer Zellen und der oben beschriebenen zellspezifischen Umwandlungsprodukte, wie sie Thoma weniger zu Gesicht gekommen, können wir der Ansicht, daß die interfibrilläre Kernverschiebung als ursächliches Moment der beschriebenen Kernanhäufung aufzufassen und daß die neugebildete Muskelfaser als das Produkt der Verschmelzung der aus den alten Muskelzellen hervorgegangenen Sarkolyten anzusehen sei, nicht beipflichten. Th o m a vertritt freilich nicht ganz apodiktisch seinen Standpunkt, wenn er schließlich zugibt, daß neben dem Zuströmen der Muskelkerne in das Verletzungsgebiet auch wirkliche Kernvermehrung in beschränkter Zahl vorkäme, indem sowohl die zugeströmten Kerne des unverletzten Sarkolemminhaltes und der Sprossen und Brücken, als auch die Kerne der Sarkoblasten gelegentlich einer mitotischen Teilung unterlägen.

Erwähnt wurde schon der neben der Entwicklung der einzelnen jungen Muskelfasern gleichzeitig einhergehende anderweitige Zerfall spezifischer Zellen, - eine Beobachtung, die die Überzeugung, daß die definitive Bestimmung der überreichlich produzierten Muskelzellen abhängig sei von der Lebensfähigkeit, 
plausibel, und die Vermutung, daß noch ein anderes Moment, vielleicht die jeweilige Intensität der funktionellen Inanspruchnahme im Spiele ist, nicht hinfällig macht. Verfolgt man das weitere Schicksal der jungen Muskelfasern, dann drängt sich dieser Gedanke erst recht auf; die unter gegebenen Umständen mitunter nachweisbare hochgradige Reduzierung der Faserzahl setzt oft genug in Erstaunen, wenn man beispielsweise ein Gebiet, das ursprünglich das Bild eines Faserkonglomerats darbot, später als feste nur noch von einzelnen, oft dazu noch atrophischen Fasern durchsetzte Bindegewebsschwiele wiederfindet. Der eben kurz skizzierte Erklärungsversuch wird uns weiter unten noch einmal beschäftigen.

Wir kehren zur Besprechung der fertigen Muskelfaser wieder zurück. Der Inhalt des Sarkolemmschlauches ist bekanntlich durch eine aus abwechselnd dunkeln und hellen Schichten gebildete Querstreifung charakteristisch gestaltet. Untersucht man das in physiologischer Kochsalzlösung konservierte, erst nach Lösung der Muskelstarre aufgefaserte Präparat, dann wird man leicht feststellen können, das diese den ganzen Faserquerschnitt durchsetzende Scheibenzeichnung sich zusammensetzt aus einer Großzahl von kleinsten, gradlinigen, räumlich neben- und untereinander geschichteten, unter sich gleichartigen, kompliziert gebauten Partikelchen; in einer charakteristischen strukturellen Veränderung dieser sogenannten Muskelelemente offenbart sich die Wirkung des funktionellen Reizes: die Muskelkontraktion äußert sich mikroskopisch in der Größenveränderung der Muskelelemente, in der Form einer Verkürzung des Höhen- und Verbreiterung des Querdurchmessers, wodurch die dunklen und hellen Felder, die doppelt- und einfach-lichtbrechenden Substanzen gleichsam auseinandergepreßt erscheinen. Die Höhenverminderung der anisotropen ist aber geringer als die der isotropen Schicht. Aus dieser Tatsache und der Feststellung, daß sich das Gesamtvolumen eines jeden Elementes während der Kontraktion nicht nachweisbar ändert, wird eine Volumenzunahme der doppeltbrechenden Substanz auf Kosten der einfachbrechenden allgemein angenommen, von Landois der weitere Rückschluß getan, daß bei der Kontraktion Flüssigkeit aus der einfachbrechenden in die doppeltbrechende Schicht übertrete; „erstere schrumpft, letztere quillt“. 
Bei Betrachtung des aufgefransten Faserpräparates könnte man die bei Beobachtung der oben mitgeteilten äußeren Um. stände gleichzeitig leicht $\mathrm{zu}$ isolierenden Faserfibrillen sich aus einer säulenförmigen Aneinanderlagerung dieser Muskelelemente entstanden denken, sie gleichsam als das Produkt eines bestimmten Umlagerungsprozesses deuten; gegen diese Annahme sprechen die früher geschilderten Beobachtungen. Die eigentliche Faserstrukturzeichnung wird in dem Regenerationsstadium der Muskelfaser durch das Auftreten anfänglich anscheinend homogener, undifferenzierter, zarter Fibrillen eingeleitet, erst nach universeller Ausbildung der Fibrillenzeichnung tritt die Querstreifung auf, offenbar als das Umwandlungsprodukt dieser Längsstreifen. Untersucht man ein Faserpräparat vielleicht dreimal 24 Stunden nach Tod des Tieres, dann ist häufig genug - ich möchte sagen : ein Dérangement intern - ein völliger Aufbruch der Faserfibrillen im Sinne einer totalen Ortsverschiebung der einzelnen Muskelelemente zu konstatieren. Bei Durchmusterung des Muskels, der in vivo von seiner Umgebung künstlich isoliert, kürzere oder längere Zeit in situ verblieb, oder der gemeinsam mit allen umliegenden Gewebeteilen unter Einwirkung ca. 7 stündiger Ischämie und nachfolgender stärkerer Gewebsdurchströmung gestanden hat, wird man nahezu alle Muskelfasern in der Richtung des Querdurchmessers ein- bzw. aufgesprengt sehen; die Aufrißebene liegt in der isotropen Substanz; diese Art Kontinuitätstrennung, die sich oft genug ohne Mitbeteiligung des Sarkolemmschlauches einstellt, zerlegt den Faserinhalt je nach Zahl der Aufbruchsebenen entweder in prismatisch-zylindroide Segmente oder sie erzeugt Bilder, die an die umgeworfene Geldrolle erinnern. In dem normalen, in Kochsalzlösung kürzere oder längere Zeit konservierten Muskel wird man nie einen ähnlichen wie den letztgeschilderten Befund erheben; mit einer besonderen Betonung dieser Feststellung möchte ich auf die variable Adhäsionsintensität der Muskelelemente bzw. auf die Abhängigkeit der Adhäsionsrichtung von bestimmten äußeren Einflüssen hinweisen. Der Effekt einer Störung dieser mehr statischen Verhältnisse der Muskelelemente wird von der Resistenz der Kittsubstanz abhängig sein; mag man nun den Konnex der Muskelelemente untereinander (Fibrillen) oder nebeneinander (Bowmans Discs) im 
Auge haben - im ersten Falle ist derselbe vermittelt durch die sogenannte End- oder Zwischenscheibe-Fibrillensubstanz, im anderen durch das Sarkoplasma, eine flüssige, feinkörnige Substanz, die alle Fibrillen einbettet, dieselben untereinander und mit dem Sarkolemmschlauche verbindet. Dieser die Muskelfaser scheinbar allseitig umschließende Sarkolemmschlauch stellt eine Isolierschicht dar, die dem Faserinhalt gleichsam den Charakter eines selbständigen Ganzen verleiht, das ideell unabhängig von den nächstbenachbarten Fasern imstande sein muß, auf irgendwelche funktionellen Reize funktionell persönlich zu antworten, womit natürlich bei Berücksichtigung des oft innigen Faserkontaktes die Vermutung, daß daneben nicht doch noch eine - ich möchte sagen funktionelle - Subordinierung der reaktionsschwächeren der kräftigeren Faser gegenüber im Sinne einer gegenseitigen Überleitung der Fasererregung zu erwarten sei, zurückgewiesen werden soll; eine vollkommenere Überleitung wäre schließlich durch partielle Verschmelzung der Sarkolemmhüllen oder noch mehr durch brückenförmige Verbindungen benachbarter Fasern bei entsprechender Unterbrechung der Kontinuität des Sarkolemms gegeben; ich habe mich freilich - gerade weil die Annahme eines ähnlichen Zustandes so verlockend ist - nie von dem Vorhandensein solcher Kommunikationsbrücken überzeugen können. Wohl sieht man häufig genug Muskelfasern, die so fest aneinander gedrängt liegen, daß von einer dieselben trennenden Sarkolemmschicht im gefärbten Präparate nichts mehr zu sehen ist; macht man aber an dem in Formalin fixierten ungefärbten Gefrierschnittpräparate den Versuch, ähnliche scheinbar miteinander verschmolzene Fasern unter dem Mikroskop mit feinen Nadeln zu isolieren, dann wird derselbe ausnahmslos gelingen; jede dieser isolierten Fasern hat ihren, wenn auch vielleicht feinen, auf jeden Fall sie scharf konturierenden Sarkolemmamantel; auch ist es nicht so selten, brückenförmige Verbindungsstücke zwischen einzelnen scheinbar normalen Muskelfasern bei oberflächlicher Betrachtung zu finden; ich sage absichtlich "scheinbar", denn in Wirklichkeit handelt es sich bei solchen Beobachtungen ausschließlich um Fasern, in denen unter dem Einflusse irgendwelcher Noxen - als solche spielen das Gewebsödem oder die Unterbrechung der Nervenbahnen eine gewisse Rolle - durch 
ein mehr oder weniger stärkeres Auseinanderweichen (Dehiszenz) einzelner Fibrillenbündel innerhalb des Sarkolemmschlauches Längsspalten auftreten, die als Faserzwischenräume, und deren Verbindungsstücke dann als Faserbrücken imponieren könnten; die der natürlichen Faserbreite mitunter gleichkommende Breite dieser Faserteile findet in der Feststellung der durch stärkere Flüssigkeitsaufnahme verursachten Dehiszenz der Faserfibrillen ihre Erklärung.

Der Kontakt der innerhalb des Muskels stets sich konisch verjüngenden Faserenden, deren Sarkolemmüberzug mikroskopisch nicht immer einwandfrei nachweisbar ist, wird durch eine Kittsubstanz vermittelt. Ähnlich ist der Übergang der Muskelfaser in das Sehnengewebe; fast immer sieht man eine ähnliche feinkörnige $Z$ wischenschicht, ob nun die korrespondierende Sehnenfaser eine ebene Endfläche zeigt oder ob dieselbe wie ein Eibecher das Muskelfaserende aufnimmt. Seltener machte ich die Beobachtung; daß die Muskelfaser kurz vor Übergang in die Sehne unter gleichzeitiger Abnahme der ovalären Kerne ihre Querstreifung verlor, mehr fibrillären Charakter annahm, um schließlich sukzessive in der Sehnenfaser aufzugehen; unter solchen Umständen erschien die Sehne weniger als ein anatomisch neues Substrat, sie konnte vielmehr als der natürliche Ausläufer des nicht mehr kontraktilen Muskelfaserendes angesehen werden. Die Muskelfasern sind entsprechend einem regen Stoffwechsel, von einem überaus reichentwickelten Kapillarnetze umsponnen, das sich in der Form langgestreckter, der Faserrichtung parallel verlaufender Gefäßmaschen den Sarkolemmhüllen anlegt; eine Anastomosierung der feinsten Arterien untereinander kurz vor Übergang in die Kapillargefäße ist nicht nachweisbar, mithin das Muskelschlagaderästchen als Endarterie zu bezeichnen. Besonders schöne Bilder von dem Verlaufe der Muskelgefäßkapillaren lieferten feinere, in Kochsalzlösung untersuchte Quetschpräparate von Muskeln, die unter der Einwirkung mehrstündiger starker venöser Stauung gestanden hatten; die Form und Zahl der Kapillarendothelkerne kann leicht bei Beurteilung der Kernverhältnisse von Sarkolemm und Sarkolemminhalt zur Täuschung verleiten. -.- Der Querschnitt der Muskelfaser - polygonal wie der der prismatischen Faserfibrillen - zeigt oft originelle Umgestal- 
tung seiner ursprünglichen Form bei Anpassung an pathologische Druckveränderung seiner Umgebung. Eine außerordentlich zarte, die Gefäßkapillaren, Nervenfasern und Lymphräume führende Bindesubstanz bildet das Faserlager, das mitunter - wie oben schon auseinander gesetzt - zwischen einzelnen Faserflächen so schwach entwickelt ist, daß man im Einzelfalle nur noch von einer Kittleiste sprechen könnte.

Soweit unsere Untersuchungen über den anatomischen Bau und die Entwicklung der Muskelfasern. Wir deuteten oben das mikroskopisch-optische Verhalten der Faserfibrillen bzw. der Muskelelemente während des Stadiums der Faserkontraktion in groben Umrissen an. Im folgenden gehen wir auf die aus der Summation der Faserkontraktionen resultierende eigentliche Muskelkontraktion ein; wir haben versucht, neben Berücksichtigung andererseits gemachter Erfahrungen soweit als möglich auch durch eigene Untersuchungen über das Wesen derselben Aufschluß zu erhalten. Eine eingehendere Beschäftigung mit dieser Frage hielten wị für notwendig, weil die reaktive Muskelverkürzung nach Applikation eines Muskelreizes der einzige Indikator für die Erregbarkeit des Muskels ist und die letztere Eigenschaft als Ausdruck des funktionellen Muskellebens uns später von Fall zu Fall immer wieder interessieren muß.

Mit Feststellung der Tatsache, daß jede Muskelfaser neben eigenen Gefäßen auch eigene, sich interfibrillär in ihr auflösende Nervenfäden besitzt, war die Auffassung, daß die Muskelfasern gleichsam als das Endorgan der motorischen Nervenfaser in ihrem Kontraktionszustande jedesmal den Effekt eines spezifischen Nervenreizes äußere, ohne weiteres geschaffen, damit also die Lehre von einer idiomuskulären Irritabilität, einer von nervösem Einflusse unabhängigen eigenartigen Muskelerregbarkeit in Frage gestellt. Daß diese These, die sich auf der exaktesten Kenntnis des intramuskulären Nervenfaserverlaufs aufbaute, bei Voraussetzung eines physiologisch normalen Nervenmuskellebens volle Gültigkeit hat, erscheint unzweifelhaft, und es ist irrelevant, ob der seiner Natur nach unbekannte, auf dem Wege der motorischen Faser eilende Normalreiz die Muskelfaser trifft, oder ob der direkte, den Muskel, damit also zugleich den Nerven selbst wieder affizierende Reiz elektrischer, thermischer, mechanischer oder 
chemischer Natur ist, - irrelevant aber freilich nur so lange, als mit Sicherheit eine Reaktion des Nerven noch angenommen werden kann; sollte im entgegengesetzten Falle, also nach Eliminierung der nervösen Reizbahn die Muskelfaser auf direkt applizierten Reiz mit einer Kontraktion antworten, dann wäre mit der Feststellung einer unter diesen Umständen noch bestehenden Muskelerregbarkeit die Vollwertigkeit der These in Frage gestellt.

Es ist bekannt, daß das Pfeilgift Curare den motorischen Nerven lähmt ohne die Reizbarkeit des Muskels selbst in besonderem Maße zu tangieren; - man könnte einwenden, es handele sich nur um Sistierung der willkürlichen Bewegung, die Muskelkontraktion nach direkter Applikation des elektrischen Stromes sei wohl oder übel doch noch auf eine Reizwirkung der wohl partiell geschädigten — Sistierung der Fortleitung des Normalreizes - damit deshalb doch noch nicht total veränderten motorischen Nerven zurückzuführen. Es ist aber auch gleichfalls nicht unbekannt, daß Muskelkontraktilität selbst nach völliger fettiger Degeneration der zugehörigen Nerven noch nachweisbar ist.

So konnte ich auch in einem Falle 39 Tage nach Resektion eines je $1,5 \mathrm{~cm}$ langen Stückes aus dem Nervus ischiadicus, N. femoralis und $\mathrm{N}$. obturatorius des Kaninchens bei maximaler Stromapplikation noch deutlich nachweisbare Kontraktionen der von diesen Nerven ursprünglich versorgt gewesenen Muskeln auslösen; bei Reizung der zu diesem $Z$ wecke wieder freigelegten, hochgradig verdünnten, derben, weißen, peripheren Nervenenden, deren Gefäßmaschen ich vor Resektion in weiter Ausdehnung absichtlich durch Abstreifung entfernt hatte, fehlte jegliche Reaktion; die Nervenquerschnitte zeigen mikroskopisch das Bild starker fibröser Degeneration. Einem Kaninchen entfernte ich das Rückenmark vom Sakralkanal an aufwärts bis in Höhe des Io. Brustwirbels dadurch, daß ich den Wirbelkanal von verschiedenen Trepanationsöffnungen aus auskratzte, weiter legte ich den rechten $\mathrm{N}$. ischiadicus bis zur Kniekehle frei, worauf dann die Abstreifung der Vasa nutritia wieder erfolgte. 30 Stunden später werden beide Hüftnerven isoliert; bei faradischer Reizung sind rechts keine, links eher gesteigerte Muskelkontraktionen auslösbar - die direkte Muskelreizung ergibt beiderseits normale Werte. Die mikroskopische Untersuchung eines dem rechten Nervus tibialis posticus entnommenen Präparates zeigt üppige, fettige Degeneration. 58 Stunden nach der Markresektion war auch links die Muskelkontraktion 
nach elektrischer Reizung des $\mathrm{N}$. ischiadicus stark herabgesetzt, 72 Stunden später eine solche überhaupt nicht mehr indirekt aus. zulösen; möglich, da $B$ die durch die Isolierung verursachte leichte Austrocknung die Leitungsfähigkeit des Nerven schon vorzeitig reduzierte. In einem zweiten Falle war ich in der Lage, noch I Io Stunden nach Markresektion bei indirekter (Nerven-) Reizung leichte Muskelkontraktionen festzustellen, i 25 Stunden nach Resektion waren aber auch diese für die indirekte Reizung erloschen, während bei direkter Applikation der Elektroden auf die Oberfläche der Muskeln noch mittelstarke Zuckungen erfolgten.

Wenn es gelang, im einen oder anderen Falle eine tiefgreifende Degeneration der Nervenbahnen nachzuweisen, dann darf wohl die Ansicht, daß auch unter solchen Umständen die bei direkter Muskelreizung auftretende Kontraktion als direkte Nervenreizwirkungen aufzufassen seien, schlechterdings als widerlegt gelten. Ich füge noch hinzu, daß ich in der Lage war, in einem Falle die Kaninchenmuskulatur bei trockener Aufbewahrung im Brutofen $\left(25^{\circ} \mathrm{C}\right) 6$ Stunden lang für die direkte Muskelreizung erregbar zu erhalten, während bei Reizung der motorischen Nerven die Muskelerregbarkeit schon 7 Minuten nach Tod des Tieres nicht mehr nachwesibar war. Persönlich messe ich noch folgendem Versuche als einem weiteren Beweise für das Bestehen einer spezifischen Muskelirritabilität besonderen Wert bei:

Man entnehme der Muskulatur eines Kaninchens ein Präparat kurz vor Eintritt der Muskelstarre, vielleicht drei Stunden nach dem Tode des Tieres - in dieser Zeit ist, wie schon erwähnt, bei indirekter elektrischer Reizung keine Kontraktion mehr auszulösen, während der Muskel bei direkt auf ihn appliziertem stärkeren Strom noch deutlich reagiert - und bemühe sich, was wohl immer gelingen wird, mit zwei Nadeln unter dem Mikroskop Muskelfasern aus dem Faserverbande röllig zu isolieren, mit anderen Worten, jeglichen Zusammenhang mit Nerv und GefäB zu sprengen; dann soll die isolierte Faser gequetscht bzw. durchschnitten, d. h. eine tiefgreifende partielle oder totale Kontinuitätstrennung geschaffen werden. Beobachtet man nun cliese so lädierte, in Kochsalzlösung suspendierte Faser eine Weile, dann wird man fast konstant folgende Beobachtung machen: über kurz oder lang, spätestens nach 25 Minuten, erscheinen zu beiden Seiten der Läsionsstelle, d. h. im Bereiche der Faserenden, knopfförmig vorspringende glänzende Wülste und oft noch im Verlaufe der Faserreststücke glänzende Ringe oder Y-förmige Bänder; bei Untersuchung dieser neuen Fasergebilde mit starken Sytsemen wird 
man mitunter mühelos in denselben eine außerordentlich feine Querstreifung bzw. enge Aneinanderlagerung der Bowmannschen Discs finden und mit der Feststellung der durch dieses enge Zusammenrücken bedingten starken Lichtbrechung die Erklärung des wachsartigen Glanzes.

Thoma, dessen ausführlichen Studien wir die Erklärung dieser Erscheinungen verdanken, führt die Wülste und Ringe auf räumlich begrenzte, mit maximaler Verkürzung einhergehende maximale Kontraktionen des Sarkolemminhaltes zurück; wir können dieser Auffassung auf Grund eigner, an größerem Material gesammelter Erfahrungen, auf die wir weiter unten noch zu sprechen kommen werden, nur beipflichten. Bei frühzeitiger Entnahme des Präparates kann man diese Versuche durch Erzeugung multipler Querschnittsläsionen an einer und derselben isolierten Faser noch weitern und wird finden, daß jedes Faserbruchstück unter Umständen wieder gleichen Läsions- bzw. Kontraktionseffekt aufweist; bei solcher Versuchsanordnung wird an der Tatsache nicht zu zweifeln sein, daß vor Eintritt der maximalen Kontraktionen der eventuelle Einfluß des motorischen Nerven schon zeitlich, d. h. durch die sofort nach dem Tode einsetzende und sich außerordentlich schnell ausbreitende Eliminierung der Nervenleitung geschwunden, dann aber auch noch die Nervenfaserenden durch die ausgedehnten Läsionen der isolierten Muskelfaser total paralytisch gemacht waren, es hätten denn sonst auf den mechanischen interfibrillen Reiz früher einsetzende maximale Kontraktionen nachgewiesen werden müssen, mit anderen Worten: die Faserkontraktionen erfolgten in diesen Fällen unabhängig von nervöser Beeinflussung. - Diese eben beschriebene, erst nach Entnahme auftretende Veränderung des Inhaltes einzelner Sarkolemmschläuche ließ sich in der Unterschenkelmuskulatur eines Patienten nachweisen, bei dem I 6 Wochen nach Läsion des Lumbalmarks durch Fraktur des Lendenwirbels II und III in einer Zeit, in der die Muskulatur bei direkter und indirekter faradischer und galvanischer Reizung völlig unerregbar blieb, eine Muskelplastik vorgenommen wurde.

$\mathrm{Zu}$ guter Letzt sei noch an die eigenartige Wirkung des Ammoniaks erinnert, Ammoniak tötet den motorischen Nerven $\mathrm{ab}$, ohne im Momente des Kontakts mit demselben eine Muskel- 
kontraktion hervorzurufen, wirkt aber prompt kontraktionserregend bei Applikation auf den Muskel selbst. Man könnte die Beweiskraft des Ammoniakversuchs angreifen etwa durch die Frage, ob nicht durch diesen chemischen Reiz in dem Muskel nur ein Umwandlungsprozeß stathabe, der mit der normalen Faserfunktion nur die Verkürzung, wie sie bẹi einer Spontangerinnung des Myosins oft genug nachweisbar und als Dauerzustand anzusehen ist, und nicht die darauf immer wieder einsetzende Erschlaffung - Rückkehr zur Ruhelage - gemeinsam habe; man könnte an die Wirkung des Chloroforms oder höher temperierten Wassers denken. Der Vergleich ist billig, anders die Wirklichkeit. Tatsächlich schwindet die durch Ammoniak erzeugte Verkürzung nach kurzer Zeit wieder, der Muskel wird schlaff, er ist freilich elektrisch nicht mehr erregbar, die Endwirkung ist mithin eine totale Faserparalyse bzw. der Fasertod. Der mit Ammoniak vorbehandelte Muskel geht aber auch nicht mehr bei Suspendierung in Essigsäure trotz Gerinnung der Muskelsubstanz - wohl aber bei Erhitzen auf $100^{\circ} \mathrm{C}$, wie ich nachweisen konnte - in Starreverkürzung über. Der in Chloroform getauchte Muskel verfällt, eben, weil die Chloroformwirkung sich in einer direkten Faserreizung und nachfolgender Myosingerinnung äußert, in Starre; er ist also nicht in der Lage, sich wieder auszudehnen.

Durch diese Tatsachen, deren Erklärung zuerst Bernstein gab, ist nun einmal erwiesen, daß das Ammoniak auf den Muskel einen Reiz ausübt, der dem physiologischen oder dem elektrischen Muskelreiz außerordentlich ähnelt, nur darin von ihm abweicht, daß nach Eintritt der Erschlaffung auf Ansäuerung oder Erwärmung auf ca. $50^{\circ} \mathrm{C}$ keine Starreverkürzung mehr sich einstellt. Wenn unsere Untersuchungstechnik vollkommen wäre und uns ermächtigte, bei der Ammoniakwirkung jeglichen Gerinnungsvorgang mit aller Sicherheit auszuschließen, dann wäre auch zu folgern, daß die Muskelverkürzung ein von der Gerinnung unabhängiger Vorgang sein muß (Bernstein). Die Gerinnung bedingt eine Zustandsänderung der Fasersubstanz, aber damit nicht immer die Kontraktion des Faserinhalts, die Starreverkürzung, wohl aber die Persistenz der Faser im Zustande der Verkürzung. 
Im Vorhergehenden haben wir versucht, die Reaktionsfähigkeit des Muskels zu skizzieren. Der Reizeffekt war jedesmal eine makroskopisch oder mikroskopisch genau wahrnehmbare Verkürzung; besonderes Interesse bot die Untersuchung der chemischen und thermischen Reize; wir konnten feststellen, daß chemische Substanzen je nach Konzentration entweder nur vorübergehende Kontraktion oder durch eindringlichere Wirkung völlige Veränderung der chemischen Faserkonstitution mit sekundärer, persistierender Verkürzung zur Folge hatten; daß weiter der Muskel bei schneller Erwärmung auf ca. $30-35^{\circ} \mathrm{C}$ sich vorübergehend verkürzt und bei stärkerer Dosierung des thermischen Reizes gleichfalls ein Starrezustand resultiert; trotz Akzeptierung der Feststellungen über den schließlichen interfibrillären Nervenfaserverlauf konnten wir uns der alten Auffassung von einer spezifischen Muskelirritabilität, die unabhängig von nervösen Einflüssen, ganz für sich besteht, nicht verschließen. Folgende Erwägung könnte vielleicht eine den Anhänger wie Gegner dieser Auffassung befriedigende Lösung bieten: Wenn sich bei Entwicklung der aktiven wie passiven Muskelkontraktion und Muskelstarre analoge Vorgänge abspielen - in beiden Fällen ist der Muskel verkürzt und verdickt, beiden das mikroskopische Kon. traktionsbild, Annäherung der Querstreifen, gemeinsam; der Inhalt des kontrahierten und erstarrenden Muskels verhält sich negativ elektrisch gegen ruhenden oder nicht erstarrten Inhalt, beide entwickeln freie Kohlensäure und die übrige Säure aus derselben Quelle (Hermann) - dann liegt die Vermutung nahe, der Muskelkontraktion einen der Starre ähnlichen Entstehungsmodus zu vindizieren: sie ließe sich als eine vorübergehende, sich wieder lösende Starre definieren (Hermann). Die eigentliche Leichenstarre ist als der Kontraktionseffekt gewisser, im Muskel postmortal entstehender Reizsubstanzen aufzufassen; dieselbe einfach als den Effekt einer Koagulation des Myosins zu beschreiben, ist eine andere, aber meines Erachtens wenig befriedigende Definition. Nun könnte man bei Übertragung unserer Auffassung von der vermutlichen wesentlichen Ursache der Leichenstarre auf die während der vitalen Kontraktion sich abspielenden Vorgänge annehmen: Die dieser Starre vorangebildeten hypothetischen Reizsubstanzen werden im lebenden Muskel durch eine 
eigenartige Reizwirkung der motorischen Nervenfasern frei diesen käme dann mehr die Bedeutung sekretorischer Fasern $\mathrm{zu}$ - und wirken dann ihrerseits, entsprechend der Konzenttrationssteigerung, koagulierend und lytisch auf das Myosin der kontraktilen Substanz, eine Hypothese, die dem Nervenreiz die Rolle des die vitale Muskelkontraktion auslösenden Moments zuschreibt, der Muskelfaser aber deshalb, weil auch in diesem Falle der Nervenreiz nur sekundär wirksam wäre, die Fähigkeit zuerkennt, auch auf andere, nicht nur den hypothetischen physiologisch-chemischen, durch den besagten Nervenreiz freigewordenen Reize, spezifisch zu reagieren.

Über das Wesen der Leichenstarre sei der Vollständigkeit halber noch folgendes als kurzes Exzerpt unserer aus dem Tierexperiment gewonnenen Eindrücke mitgeteilt:

Im Interesse einer anschaulichen Demonstration rekurrieren wir zweckmäßig zuerst auf ein unter dem 10. IX. I9IO aufgezeichnetes Protokoll, das gleichzeitig bisherige Mitteilungen über die Veränderung des physiologischen Verhaltens des Muskels ergänzt. Um I2 Uhr wird ein Kaninchen durch Nackenschlag abgetötet, der Kadaver enthäutet bei $25 \mathrm{Grad}$ C. trocken aufbewahrt. Die sofort nach Eintritt des Todes vorgenommene elektrische Muskeluntersuchung ergibt keine abnormen Ausfallserscheinungen sowohl bei direkter wie indirekter Reizung. Der Muskel ist rot, glasig-transparent; bei Incision erfolgen auf prompte Retraktion der Schnittenden, wie immer bei Untersuchung lebendfrischen Materials, fibrilläre Zuckungen. Die Faserisolierung im Zupfpräparat ist durch starke, ich möchte sagen, mehr elastische Adhärenz der F asern sehr erschwert. 12,07 wird bei Nervenreizung keine Kontraktion mehr ausgelöst; prompte Muskelzuckung bei direkter Muskelreizung; um I Uhr nur noch Retraktion der Schnittenden, keine fibrillären Zuckungen einzelner Faserbündel; um 2 Uhr bei maixmaler Reizung mittelkräftige, um 3 Uhr deutlich verlangsamte, aber immerhin noch sinnfällige Kontraktion; um $4 \mathrm{Uhr}$ ist die Muskelreaktion noch angedeutet und von auffallend geringer Dauer, ein leichter Starrezustand schon nachweisbar; um 4,30 ist die Muskelkontraktion nach direkter, maximaler Reizung $=0$. Zwei Stunden nach Tod des Tieres ist der Muskel blaßrot, weniger transparent, die Auffaserung des Muskelpräparates bzw. die Faserisolierung leichter; $4 \frac{1}{2}$ Stunden später läßt sich das Präparat mühelos zerlegen; die Faserbündel erscheinen makroskopisch trüb-weißlich. Fünf Stunden nach Tod sind die Extremitäten starr, die Gelenke in leichter Flexionsstellung fixiert, die Muskeln sind verkürzt und verdickt, von auffallend derber Konsistenz; es ist aber keine Retraktion der Schnitt- 
enden mehr festzustellen; dieselben sind im Vergleich zur Muskeloberfläche auffallend feucht; die auf den Schnittflächen zutage tretende Flüssigkeit (Muskelserum) färbt blaues Lackmuspapier deutlich rot. In diesem Starrezustand zeigt der Muskel bei mikroskopischer Untersuchung des in physiologischer Kochsalzlösung suspendierten Zupfpräparates folgendes Bild: Die Muskelfasern sind leicht gelb tingiert; die Fasertransparenz ist hier und da abgeschwächt; die Querstreifen sind stärker aneinander gerückt; neben Fasern mit der charakteristischen Scheibenzeichnung findet man häufig solche mit scharf ausgeprägter, fibrillärer Struktur und entsprechender Verschiebung der Muskelelemente sowie Verzerrung der Querstreifen. Zeichen von Reaktion auf den durch die Auffaserung gesetzten mechanischen Insult in der Form der oben beschriebenen Kontraktionswülste und Reize fehlen: Die reaktive Faserfunktion ist in diesem Zustande vollentwickelter Leichenstarre als erloschen zu betrachten. In einzelnen Präparaten erschienen die Faserfibrillen verdickt und verkürzt, wie gequollen; ich faßte nicht ohne Grund diese Beobachtung schärfer ins Auge und fahndete nach weiteren ähnlichen Bildern, freilich ohne besonderen Erfolg.

Nehmen wir einmal an, dieser Befund wäre konstant, der bisher geschilderte nur akzidentell gewesen, dann hätten wir unsere Auffassung von der Entstehung und dem Wesen der Muskelstarre gründlich revidieren müssen, ev. folgende These aufstellen können: die Muskelstarre ist der Ausdruck eines durch Milchsäurewirkung ausgelösten Quellungsprozesses und nicht der Effekt der Myosingerinnung; in einer Gerinnung des Faserinhaltes beruht vielmehr die Lösung der Starre. - Diesen Gedanken, der sich in völligen Gegensatz zu unserer bisherigen Auffassung stellt, mußten wir eben mit Rücksicht auf das nur vereinzelte Vorkommen derart veränderter Muskelfasern naturgemäß wieder fallen lassen.

Wenn es angebracht ist, ganz allgemein zwei Stadien der Starre zu unterscheiden, ein erstes, in dem der Muskel bereits schon etwas steif, aber noch reizbar ist (s. oben) und ein zweites, in dem die Starre manifest, charakterisiert durch die vorerwähnten Symptome, dann darf doch noch nicht aus der Feststellung des zweiten Stadiums einschließlich der Faserparalyse ohne weiteres völliger Fasertod gefolgert werden. - Dieser Satz hat seine Berechtigung, wenn es experimentell gelingen sollte, am lebenden Tiere eine der Definition entsprechende Muskelstarre zu erzielen und gleichgültig, unter welchen Umständen - Regenerationserschei- 
nungen wieder festzustellen; weiter unten werden wir diese Frage wieder aufnehmen.

Die Leichenstarre ist nun bekanntlich kein Dauerzustand; über kurz oder lang (beim Kaninchen im Durchschnitt zwischen I 8-32 Stunden), im vorliegenden Falle ca. 20 Stunden nach Eintritt der Starre, setzt die Lösung ein - das geronnene Myosin ist wieder unter der Einwirkung chemischer Umsatzprodukte in den flüssigen Aggregatzustand übergeführt. Die Reaktion des schließlich wieder völlig erschlafften Muskels ist deutlich alkalisch. Mikroskopisch zeigt derselbe wieder gute Fasertransparenz, exakte Querstreifung, normale Scheibendistanz. Der Faserquerschnitt ist während und nach Lösung der Muskelstarre etwas reduziert. Mit der Lösung des Myosins ist der Faser eine gewisse Reaktionsfähigkeit wiedergegeben. Durch künstliche Neuschaffung eines Gerinnungszustandes ist wieder, wie der Versuch zeigt, eine neue Muskelkontraktion zu erzielen. Erwärmt man beispielsweise ein nach Lösung der Starre entnommenes Muskelpräparat, dann nimmt dasselbe ungefähr bei $70-80^{\circ} \mathrm{C}$ Wassertemperatur spontan Weißfärbung an, und nahezu synchron mit der Gerinnung, von der natürlich alle Faseralbuminate befallen werden, tritt eine Kontraktion ein, durch die das Präparat auf ca. ein Drittel seiner ursprünglichen Größe reduziert wird ein Zustand, dem der lebendfrische Muskel schon bei einer Er-

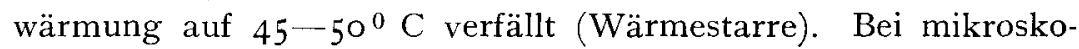
pischer Untersuchung derart vorbehandelter Muskelpräparate, die sich auf dem Objektträger außerordentlich fein zerzupfen lassen, ist konstant folgender Befund zu erheben : Die Fasern, meist stark gewunden, sind ausnahmslos braun-gelb verfärbt, auffallend ist die hochgradige Annäherung der scharf konturierten Querstreifen sowie die starke Verschmälerung. Wir haben somit das typische, aber extrem gezeichnete Bild eines postmortalen Faserkontraktionszustandes vor uns, das von dem vitalen, charakteristisch einmal durch die Färbung und veränderte Transparenz, vor allem aber durch die starke Reduzierung des Faserquerschnitts unter. schieden ist; letzteres Symptom ist sicherlich auf stärkere Flüssig. keitsabgabe des Sarkolemminhaltes zurückzuführen und interessiert uns besonders, weil es das mikroskopische Muskelbild eines klinisch beobachteten Falles souverän beherrschte. 
Es handelte sich um eine ausgedehnte Verbrennung des Kopfes, der Brust und beider oberen Extremitäten bei einem I 2 jährigen Mädchen, das $2^{1 / 2}$ Stunden nach Unfall (Lampenexplosion) ad exitum kam. Das Eigenartige an diesem Falle war die extreme Kontrakturstellung sämtlicher Gelenke der oberen Extremitäten; die Grundglieder von Finger $2-5$ standen in leichter Dorsalflexion; die Mittelund Endglieder waren krallenförmig in die Hohlhand eingeschlagen; die trockne, braun-schwarze, nicht verkohlte Haut umspannte die leicht gewulsteten, brettharten, druckschmerzhaften Muskeln, die keine aktive oder passive Beweglichkeit zeigen; an der Leiche ließ sich erst nach Durchtrennung der Sehnen oder Muskeln die Kontrakturstellung beheben. Bei anatomischer Präparation einer Extremität ergab sich, daß die Haut derb wie Leder und das Unterhautzellgewebe stark verflüssigt - eigentümlich bräunlich tingiert war. Die oberen Muskelschichten, sowohl des Ober- wie Vorderarmes, waren braungrau, die tieferen wieder mehr normal rot gefärbt. Das arterielle Gefäßsystem war, soweit als makroskopisch nachweisbar, blutleer; in den Hautvenen steckten fadenförmige Gerinnsel, die tiefen Blutadern tührten mittelgroße Mengen flüssigen dunklen Blutes. Die Nervenstränge zeigten keine auffallende Veränderung. Der eben erwähnte Farbenunterschied der oberflächlichen und tiefen Muskelschichten am Vorderarm der der oberflächlichen und tiefen Flexoren - ist direkt eklatant und charakteristisch, weniger auffallend eine besondere Differenz in den mikroskopischen Bildern der diesen einzelnen Muskelschichten entnommenen Muskelfasern. Die mehr peripher gelegenen Fasern erscheinen wohl in toto mehr rauchig getrübt und weniger transparent, als die tiefer gelegenen, auch kann man in den oberflächlichen Schichten häufig innerhalb der Sarkolemmaschläuche größere Strukturveränderungen im Sinne eines früher beschriebenen Dérangement interne der Muskelelemente, das freilich bei Zusatz von Essigsäure zu dem in Kochsalzlösung untersuchten Zupfpräparate wieder ebenso wie die stärkere Trübung schwindet und nahezu normaler Faserzeichnung Platz macht, nachweisen. Den oberflächlich wie den tief gelegenen Muskelfasern aber gemeinsam ist die starke Verschmälerung und die aus der Reduktion der Faserdicke resultierende relative Kernvermehrung, der außerordentlich dichte Scheibenkonnex sowie die starke Prominenz der Sarkolemmakerne. Die einzelnen Fasern, die als absolut reaktionslos zu bezeichnen sind - wenn der Nachweis der posttraumatischen, oben skizzierten Faserveränderung als Kriterium für die Faserreaktionsfähigkeit gelten soll - sind of wie auseinander gesprengt; die stärkere Diastase derselben ist auf das Auftreten freier Gewebsflüssigkeit zurückzuführen, deren Ursprung wieder mit stärkerer Transsudation der Blut- und Lymphgefäße oder mit dem Austritt von Serum aus den Muskelfasern selbst in $\mathrm{Zu}$ sammenhang zu bringen wäre. Gegen die erste Annahme spricht die 
Beobachtung, daß kleinere oder größere Lücken gerade nur innerhalb der Faserbündel, d. h. nur zwischen den Muskelfasern, weniger in den Interstitien der Faserbündel (Perimysium internum) nachweisbar sind. Die letztere Annahme fand ihre besondere Stütze in der Feststellung der auffallenden Reduzierung des Faservolumens. Dieser Austritt von Muskelserum - das ist eine bei Gerinnung der Muskelsubstanz vom Myosin sich scheidende Flüssigkeit, durch deren Übertritt aus der isotropen in die anisotrope Schicht bei gleichzeitiger Gerinnung der kontraktilen Substanz sich die Verbreiterung der anisotropen Schicht im Stadium der Kontraktion erklären läßt - erscheint erst bei Voraussetzung pathologisch gesteigerter Durchlässigkeit der Sarkolemmahülle möglich; er setzt wahrscheinlich erst nach totaler Myosingerinnung und Faserkontraktion bei Fortwirkung der Faserüberhitzung - Faserdörre - ein.

Geht man der Entstehung der in vorliegendem Falle näher beschriebenen, intra vitam entstandenen Muskelstarre nach, dann ließe sich unter besonderer Berücksichtigung der kurzen Zeitspanne, in der die Kontrakturen manifest wurden - nach Angaben der Angehörigen befanden sich die Extremitäten schon sofort nach Erstickung des Brandes in der oben beschriebenen Stellung -, vermuten, daß die primäre Entstehungsursache in einer unter der tiefergreifenden Überhitzung spontan einsetzenden Myosingerinnung der oberflächlich gelegenen Muskeln zu suchen ist; auf denselben, in der Tiefe natürlich schwächer dosierten thermischen Reiz ist wohl auch die Myosingerinnung der tiefer gelegenen Muskeln zurückzuführen. Die arterielle Anämie kommt u. E. schon wegen des frühzeitigen Auftretens der Kontrakturen als ursächliches Moment der Myosingerinnung im Bereiche auch der oberflächlichen sowie der tiefen Muskelschichten nicht in Betracht. Die Frage, ob die arterielle Anämie und venöse Oligämie auf rein reflektorischem Wege zustande gekommen ist oder nicht, haben wir nicht weiter untersucht. Die Gerinnselbildung in dem Hautvenennetz ist auf jeden Fall direkter Verbrennungseffekt. Die Nichtanerkennung eines ursächlichen Zusammenhanges dieser Muskelstarre mit der Sistierung der Zirkulation ist durch entsprechende praktisch-experimentelle Erfahrungen zu begründen. Wir nehmen das zur Erledigung dieser Frage besonders interessierende Ergebnis vorweg, wenn wir schon jetzt darauf hinweisen, daß in all den Versuchen, in denen es uns gelang, durch Zirkulationsunterbrechung Muskeln künstlich 
in den Starrezustand zu versetzen, die Starre aber immer erst nach einer geraumen Zeit, nie so plötzlich als in dem Verbrennungsfalle einsetzte.

Bei Untersuchung der Frage, in welcher Weise der Muskel auf die Zirkulationsunterbrechung antworte, sind die einzelnen Autoren auf verschiedenen Wegen vorgegangen.

$\mathrm{S}$ te n s on unterband als erster bei dem Tiere die Aorta abdominalis; kurze Zeit nach der Ligatur konnte er eine Lähmung der hinteren Extremitäten konstatieren, die aber wieder nach frühzeitiger Lösung derselben verschwand; bei länger dauernder Stromunterbrechung trat die Muskelstarre auf. Andere Autoren suchten und fanden durch isolierte Unterbindung der einzelnen Muskelarterien ähnlichen Effekt; so sah bei diesem Vorgehen Stannius nach einer Stunde die Reizbarkeit der motorischen Nerven, nach $4-5$ Stunden die der Muskelsubstanz selbst schwinden; ,hieran schließt sich dann die Starre" (L a n dois). Diesen letzten Versuch haben wir in folgender Weise modifiziert. Bei einem narkotisierten Kaninchen wurde der Musculus tibialis anticus und extensor digitorum communis jeder für sich total isoliert; dann zwecks Gefäß- und Nervenausschaltung der M. tibialis in seinem proximalen noch muskulären Endteil, der M. extensor kurz vor Übergang in die das Kniegelenk frei durchziehende proximale Sehne mit Seidenfäden fest ligiert; die Gefäße der peripheren Sehnen wurden bis in die Höhe des Fußrückens abgestreift, daraufhin die Muskeln einzeln in sterile Katgutplatten eingehüllt; das Ergebnis der elektrischen Untersuchung, die vermittels zweier nadelförmiger auch nach SchluB der Hautnaht durch Nahtlücken hindurch direkt auf den Muskel geführten Elektroden vorgenommen wurde, war folgendes: Sofort nach Isolierung zuckt der Muskel prompt, eine Steigerung seiner Kontraktilität ist freilich nicht nachweisbar; fünf Minuten später ist die Zuckungsintensität und Zuckungsdauer schon deutlich abgeschwächt; nach 30 Minuten ist eine Muskelkontraktion bei mittelstarker, $2^{1} / 2$ Stunde später erst bei maximaler Reizung noch prompt auszulösen; $3^{1 / 2}$ Stunde nach Isolierung ist die elektrische Erregbarkeit erloschen; ca. sieben Stunden später stehen Zehen und FuB bei Ohrhängelage des Tieres in leichter Dorsalflexion deutlich fixiert; sie beharren in dieser Stellung auch bei Narkotisierung des Tieres - die beiden Muskeln befinden sich im Zustande der Starre. 20 Stunden nach Eintritt dieser Starre werden bei Bewegungsversuchen $\mathrm{FuB}$ und Zehen in schlaffer Plantarflexion nachgeschleppt. Vier Tage nach Operation erfolgte die öffnung der lineär verklebten Wunde; Entzündungserscheinungen waren makroskopisch nicht festzustellen. Die beiden Muskeln, deren Katgutbekleidung teilweise mazeriert, teilweise etwas abgeglitten ist, werden in toto exstirpiert. Die Muskeloberfläche 
zeigte ein buntscheckiges Aussehen: der grau-rosa Grundton war von verschieden abgestuften roten Flecken (alte Blutextravasate) durchsetzt; bei Einschneiden erweist sich der Muskel als gummiartig derb konsistent und auffallend trocken. Die elektrische Erregbarkeit war natülich erloschen; die Fortleitungsfähigkeit für den elektrischen Strom aber noch gut erhalten. Bei mikroskopischer Untersuchung des in Kochsalzlösung konservierten sowie des sofort nach Entnahme in Formalin fixierten und gefärbten Präparates zeigen die Muskelfasern der peripheren Schichten ausgedehnte Fragmentierung — größtenteils diskenförmigen Aufbruch, vereinzelt Faseraufspaltung in der Richtung des Längsdurchmessers - sowie ausgedehnte Kerndegeneration; in den Faserzwischenräumen sind größere oder kleinere Mengen von Kernsplittern suspendiert, hier und da verstreut liegende, gut konfigurierte Leukocyten, offenbar von der Muskeloberfläche in die Tiefe gewandert; die Faser- und Kernfragmentierung ist in den tiefer gelegenen Muskelschichten weniger stark entwickelt; daselbst kann man einen ausgeprägten fibrillären Typus und häufig genug noch normal konturierte Faserkerne nachweisen. Im Oberflächenbezirk sieht man - allerdings nur vereinzelt - neben Fasern mit typischen Kontraktionswülsten auch solche im Stadium des diskoiden Zerfalls, andere Sarkolemmaschläuche sind von stark gequollenen homogenen Massen angefüllt. Wir zweifeln nicht daran, daß nach kürzerer oder längerer Zeit auch die tiefer gelegenen, anatomisch noch normal aussehenden, physiologisch aber toten Muskelfasern den oben beschriebenen Fragmentierungsprozeß erfahren haben würden bei Voraussetzung eines weiteren Vordringens der von dem umliegenden Gewebe aus durch Lücken der Isolierschichten hindurch in die Muskeln iibergegangenen Lymphflüssigkeit; auf eine ähnliche Durchspülung teilweise oder völlig abgestorbenen Muskelgewebes ist in Wirklichkeit - wie noch auseinandergesetzt werden soll - dieser Faserauflösungsprozeß zurückzuführen.

Den sog. Stensonschen Versuch habe ich in der Hoffnung, über die sekundären Ausfallserscheinungen des Nerven- und Muskelapparates eine einheitlich bündige und befriedigende Auskunft zu erhalten, im ganzen 13 mal wiederholt. Eine ausführliche, alle Einzelheiten summierende Schilderung unserer Beobachtungen halte ich deshalb für angebracht, weil einmal die Literatur in dieser Frage selten mehr als nur kurze, die augenscheinlichsten Reaktionen rekapitulierende Notizen bringt, mir wenigstens ist es trotz eifrigsten Nachforschens nicht gelungen, eine detaillierte Beschreibung dieses Experiments zu erhalten; das Hallersche Werk ,Elementa physiologica“, in dem über den Stensonschen Versuch berichtet wird (Leser), stand mir 
nicht zur Verfügung, dann aber auch unsere experimentellen Ergebnisse bei Berücksichtigung der Nutzanwendung, die man von einem temporären Aortenverschluß gemacht, einem gewissen klinischen Interesse begegnen dürften. Einzelne Punkte dieser Schilderung werden wir später bei Untersuchung der ischämischen Muskelveränderung noch einmal repetieren müssen.

Die Absicht, im Interesse einer exakten Beobachtung störende Nebenwirkungen auszuschalten, veranlaßte uns unter anderem, wenn anders es nicht unumgänglich notwendig war, bei Freilegung der Aorta extraabdominell vorzugehen. Intraabdominelle Eingriffe haben nach meinen Erfahrungen gerade bei dem $\mathrm{Ka}$ ninchen oft genug längerdauernde Chokwirkung zur Folge. In 6 Fällen gingen wir in folgender Weise vor:

Der Hautschnitt wird links von der Medianlinie von der Höhe des I. bis zum 5. Lendenwirbel dicht neben den stark vorspringenden, den Processus spinosi nächstbenachbarten und ungefähr parallel gerichteten Fortsätzen bis auf die Muskelfascie geführt; die Muskulatur mit rechtwinklig abgebogenen Raspartorien von den Fortsätzen und Wirbelbögen abgeschabt und in toto zur Seite geschoben, dadurch in der Tiefe die je nach Alter des Tieres $2-3 \mathrm{~cm}$ langen, schräg nach vorn und kaudalwärts gerichteten Processus costarii von Lendenwirbel 2 und 3 freigelegt, letztere dann in ihrer Wurzel durchtrennt, seitlich luxiert und durch Scherenschlag von den an die inserierenden Muskeln definitiv gelöst; nach Resektion der flachen Muskeln, die ursprünglich zwischen diesen Fortsätzen ausgespannt waren, dringt man unter Zurückschiebung bzw. partieller Abtragung des M. quadratus lumborum direkt zu den Wirbelkörpern vor, worauf es dann bei genügender Vorsicht nicht besonders schwer fällt, unter Schonung des parietalen Peritoneums die Aorta in genügender Ausdehnung aus ihrem lockeren Gewebslager herauszuheben und nach vorsichtiger Isolierung von der dicht anliegenden $\mathrm{V}$. cava, sie doppelt zu ligieren. Die Ligaturen saßen bei diesem Vorgehen jedesmal unterhalb der Abgangsstelle der linken Nierenarterie. Sofort nach Knotenschluß erweiterte sich der proximale Endteil der Aorta mehr weniger unter sichtbar verstärkter und vermehrter Pulsation; im gleichen Momente kollabicrte der periphere Teil; dieser spontane Kollaps ließ sich bei transperitonealem Vorgehen in einem Falle bis zur Teilungsstelle der Aorta verfolgen; die Vena cava schwillt nach Ligatur zusehends ab.

Das erste augenfällige Symptom nach Unterbrechung der Zirkulation im Bereiche der hinteren Extremitäten ist die meistens 
sofort einsetzende Lähmung derselben: in zwei Fällen erwachte das Tier jedesmal unter lebhaftem Schrei bei Schluß der Ligatur, die im selben Momente sich einstellenden Abwehrbewegungen gingen ausschließlich von den vorderen Extremitäten aus; die Hinterbeine beharrten in der jeweilig ihnen gegebenen Lage; ungefähr gleichzeitig mit dem Ausfall der willkürlichen Bewegungen sistierten der Patella- und Kremasterreflex. Brachte man das noch narkotisierte Tier sofort nach Operation in Ohrhängelage, dann erfolgte in 7 Fällen spontane Blasenentleerung, in 2 Fällen wurde Urinretention festgestellt; bei Obduktion war jedesmal die Blase extrem gefüllt. Die Lebensdauer der Kaninchen differierte nach Unterbindung der Aorta zwischen I6 bis 42 Stunden, von 2 Fällen abgesehen, bei denen die Ligatur nach 7 bzw. Io Stunden wieder gelöst wurde. Sämtliche Tiere waren nach Operation auffallend apathisch; das vorgeworfene Futter wurde keinmal angerührt, dagegen Wasser oft geradezu gierig geschlürft. Die Körperwärme war bald nach' dem Eingriff unterhalb der in der Höhe der Ligatur durch den Körper gelegten sagittalen Ebene in verschiedener Abstufung überall herabgesetzt; so betrug dieselbe in einem Falle bei oral gemessener Normaltemperatur von $38,2^{\circ}$ in dem Rektum $35,0^{\circ}$, in der Leistenbeuge $37,4^{0}$, in einem anderen Falle gleichfalls 5 Stunden nach Unterbindung rektal $35, \mathrm{I}$, in der Leistenbeuge $37,2^{\circ}$. Die wichtigste, den Tod jedesmal ankündigende Prodromalerscheinung war der gewöhnlich 2-3 Stunden vorher plötzlich einsetzende starke Temperaturabfall im Bereiche des proximalen Körperteiles; die Temperaturgrenzen lagen zwischen $36, \mathrm{I}$ und $35,2^{\circ}$. Der bei jedem Tier mehrfach untersuchte Urin, der auch später bei Ohrhängelage jedesmal spontan abfloß, dann aufgefangen wurde, enthielt ausnahmslos kleinere oder größere Mengen Eiweiß; im Sediment waren rote und weiße Blutkörperchen, Blasenepithelien sowie mineralische Bestandteile nachweisbar. Der Blutgehalt des Urins war durch mehr oder weniger ausgebreitete Stauungsblutungen der Blasenschleimhaut bedingt; auf eine ähnliche Affektion der Colonschleimhaut ist der mehrfach festgestellte Blutgehalt des in solchen Fällen jedesmal ungeformten Kotes zurückzuführen.

Von allen postoperativen Erscheinungen interessiert uns naturgemäß am ehesten das Verhalten der Muskeln und Nerven; 
wir erwähnten schon die nach Ligatur der Aorta spontan einsetzende Lähmung der willkürlichen Bewegungen der hinteren Extremitäten sowie die Sistierung der Patellareflexe. Diese Ausfallserscheinungen sind wohl oder übel als Effekt plötzlich auftretender Anämie des Rückenmarks anzusehen. Direkt schlaff kann man diese Lähmung nicht eigentlich bezeichnen - man braucht nur das Tier bei seinen Fortbewegungsversuchen zu beobachten und wird stets feststellen können, daß Fuß und Unterschenkel - anders als nach Resektion peripherer motorischer Nerven - in leichter Flexionsstellung nachgeschleift werden, mit anderen Worten, daß immer noch eine gewisse mittlere Muskelspannung besteht. Um über die reaktive Einstellung der Muskeln und Nerven nach der künstlich geschaffenen Zirkulationsunterbrechung Aufklärung zu erhalten, sahen wir uns verpflichtet, die elektrische Erregbarkeit von Fall zu Fall in bestimmten Intervallen (auch während der Nachtstunden) nachzuprüfen; Jabei kamen wir, wenn wir die im Einzelfalle gemachten Beobachtungen summarisch wiedergeben sollen, zu folgendem Endergebnis: Die elektrische Erregbarkeit der Muskeln ist kurz nach Ligatur normal; eine Steigerung derselben wurde in keinem Falle weder bei direkter noch bei indirekter Reizung wahrgenommen. I Stunde später ist die Muskelkontraktion bei direkter Faradisierung schon schwächer; bei indirekter noch nahezu normal. Die Muskelerregbarkeit geht in der Folgezeit bei direkter Applikation der Nadelelektroden kontinuierlich schneller zurück als bei Reizung der betreffenden motorischen Nerven, und eigentümlicherweise zeigt die rechte hintere Extremität stärkere Progredienz dieser Ausfallserscheinungen als die linke. Nach 4 Stunden zuckt der Muskel durchschnittlich bei Stromstärke I 40 und direkter sowie bei Stromstärke 30 und indirekter Faradisierung. 7 Stunden nach Ligatur ist die Muskelerregbarkeit bei direkter Reizung stärker, bei indirekter kaum nennenswert herabgesetzt; Io Stunden später ist in ungefähr allen Protokollen „Status idem" vermerkt; nach I 2 Stunden werden bei Stromstärke 40 und indirekter Reizung noch deutliche Kontraktionen ausgelöst, bei maximaler Stromstärke und direkter Applikation ist die Muskelzuckung noch eben wahrnehmbar; bislang beschrieben wir die Erregbarkeit der Ober. schenkelmuskeln. Die Erregbarkeit der Unterschenkelmuskulatur 
schwindet schon frühzeitiger, derart, daß nach 12 Stunden im Durchschnitt eine Kontraktion - beispielsweise der Zehenstrecker - erst bei Stromstärke I 20 und indirekter Faradisierung, und zwar nur linkerseits bemerkt wurde; bei direkter Reizung war auch links keine Muskelzuckung mehr auslösbar. I 5 Stunden nach Ligatur war bei einem Tiere, das I Stunde später ad exitum kam, die elektrische Erregbarkeit der Ober- und Unterschenkelmuskeln bei direkter und indirekter Prüfung erloschen. Nach 24 Stunden war in 3 Fällen die Kontraktionsfähigkeit der Unterschenkel aufgehoben, die des rechten Oberschenkels bei maximaler indirekter Reizung noch eben angedeutet, die des linken bei Stromstärke I 20 und gleichfalls nur noch bei der Nervenreizung wahrnehmbar; gleichzeitig waren - um diese Beobachtungen noch hier einzuflechten - die hinteren Bauchmuskeln fast total gelähmt, damit von dem Atemakt ausgeschlossen; im Bereiche der hinteren Extremitäten und des Hinterleibes bis in Höhe der Ligatur bestand völlige Analgesie. Nach 34 Stunden war nur noch in einem Falle bei maximaler, aber diesmal direkter Reizung eine schwache, verlangsamte Kontraktion der Adduktoren des linken Oberschenkels festzustellen; der Hautbezirk oberhalb der Ligaturebene erschien in Handbreite hyperalgetisch; bei leichtem Kneifen einer aufgehobenen Hautfalte schrie das Tier jedesmal laut auf. Im Vergleich zu der progredienten, schließlich totalen Paralyse sämtlicher Extremitätenmuskeln besteht die Zuckungsfähigkeit des M. cremaster erstaunlich lange fort; bei dem Versuchstier, das erst 24 Stunden nach Ligatur starb, konnte ich noch 2 Stunden vor dem Tode durch mittelstarke Ströme deutliche Kontraktionen auslösen. Dieser mich anfänglich überraschende Befund fand aber eine einfache Erklärung in der Feststellung außerordentlich günstiger Zirkulationsverhältnisse.

Für diesen Muskel kommt als ernährendes Gefäß in erster Linie die Art. spermatica externa in Frage; diese entspringt aus der Arteria epigastrica inferior, die ihrerseits wieder mit der Art. epigastrica superior kommuniziert und somit nach Ligatur der Aorta die $\mathrm{Zu}$ führung arteriellen Blutes aus dem proximalen Teile der großen Körperschlagader ermöglicht; sollten Kommunikationsäste zwischen der Art. spermatica externa und interna bestehen, dann wäre dazu noch die Möglichkeit einer Blutversorgung von letzterem Gefäße aus gegeben. Die rechte Art. spermatica interna entspringt beim 
Kaninchen direkt aus der Aorta unterhalb der Abgangsstelle der Art. renalis; die linke ausnahmslos aus der Arteria renalis selbst. In allen Fällen wurde bei Ligatur der Aorta die linke Hodenarterie geschont.

In ähnlicher Weise erklärt sich die noch relativ spät nachzuweisende Erregbarkeit der Adduktoren - durch den Ramus pubicus der Arteria obturatoria ist - wie wenigstens beim Menschen bestimmt nachgewiesen — eine Kommunikation mit dem gleichnamigen Ast der Art. epigastrica inf. geschaffen. Diese letzten Feststellungen erklären auch einen scheinbaren Widerspruch. Vergleicht man den Effekt der direkten und indirekten Muskelreizung nach Aortenligatur mit den früher mitgeteilten Ergebnissen, dann könnte der nicht zu verkennende Unterschied den Beurteiler bei Bewertung der einzelnen Resultate wohl stutzig machen.

Bei Besprechung der postmortal noch auslösbaren Muskelreaktionen führten wir an, daß geraume Zeit nach Erlöschen der Nervenfunktion der Muskel bei direkter Reizung noch prompt sich zusammenzieht. In den zuletzt geschilderten Versuchsergebnissen liegen die Verhältnisse geradezu umgekehrt. So konnten wir feststellen, daß die Muskeln der hinteren linken Extremität noch bei indirekter Faradisierung und geringer Stromstärke sich kontrahierten in einem Momente, wo zur Auslösung minimaler Muskelkontraktionen bei direkter Stromapplikation schon maximale Stromstärke erforderlich war. Diese Untersuchungsergebnisse hätten befremdend wirken müssen, wenn eben mit der Ligatur der Aorta eine alle Gewebe, Muskeln und Nerven gleichmäßig tangierende Anämie garantiert gewesen wäre. Gewiß, der nach Unterbindung des arteriellen Hauptstromes spontan einsetzende Ausfall der Funktion der Centra des unterhalb der Ligaturebene gelegenen Rückenmarksabschnittes, könnte als Reaktion auf plötzlich entstandene Anämie dieses Bezirkes imponicren. Wenn theoretisch nach Lage der Zirkulationsverhältnisse im Lenden- und Sakralmark eine totale Anämie überhaupt zu konstruieren ist - der arterielle Gefäßüberzug des Rückenmarks ist doch schließlich ein Netz miteinander kommunizierender Spinaläste - , dann wird man wohl annehmen dürfen, muß über kurz oder lang nach definitiver Sistierung der arteriellen Zufuhr aus den Rami spinales lumbales et sacrales vikariierend ein 
verstärkter Afflux aus dem höher gelegenen nach dem anämischen tiefer gelegenen Gefäßbezirk zu statthaben, vorausgesetzt, daß unter dem Einflusse der postoperativen Chokwirkung der Blutdruck nicht eine permanente Abschwächung erfahren hat. Diese hypothetische Zeit einer wirklich totalen Zirkulationsunterbrechung, unter deren Wirkung die plötzlichen Ausfallserscheinungen zu setzen wären, ist in Wirklichkeit zu kurz, um eine tiefer greifende organische Schädigung des gewiß gegen Zirkulationsveränderungen äußerst subtilen Gewebes aufkommen zu lassen. Der Funktionsausfall darf nicht als Ausdruck des Gewebstodes gedeutet werden. Folgender Versuch spricht für die eben aufgestellte Behauptung.

Bei einem Kaninchen wird $4^{1} / 2$ Stunde nach Ligatur der Aorta (Rückenschnitt) der Unterbindungsknoten wieder gelöst; drei Tage später werden promptere Muskelkontraktionen bei direkter und indirekter Reizung festgestellt, nach I8 Tagen die ersten selbständigen Bewegungen der hinteren Extremitäten beobachtet; heute, ca. sechs Monate nach Ligatur, sind keine Ausfalls- oder Reizerscheinungen mehr vorhanden; der Patellareflex ist gut auszulösen. Ein anderes Versuchstier, bei dem ich erst nach achtstündiger Ligatur den Strom wieder freigab, starb, ohne nennenswerte Änderung gegenüber dem vor Lösung erhobenen Befunde zu zeigen, ca. vier Tage später.

Diese Versuche besagen, daß neben der Wiederkehr normaler Funktion der Rückenmarkszentren nach $4 \frac{1}{2}$ stündiger Unterbrechung des Aortenstromes auch bei länger dauernder Unterbrechung vitale Vorgänge in dem Rückenmark trotz Unterernährung wohl noch unterhalten werden. Von diesem Gesichtspunkte aus ist auch den peripheren Nerven wohl noch ein gewisser Reizzustand zu supponieren, hinzu kommen die relativ günstigen Ernährungsbedingungen, unter denen, wenigstens der linke N. ischiadicus, trotz Schädigung des Sakralmarkes sich eine gewisse Selbständigkeit und Ausdauer zu bewahren in der Lage ist. Der linke Hüftnerv erhält ebenso wie der rechte ein ernährendes Gefäß aus einem Aste der Art. glutaea inferior, daneben aber noch, wie ich durch Injektionsversuche 2 mal einwandfrei feststellen konnte, kurz vor Passage aus dem Foramen ischiadicum einen kleinen Ast aus der Art. spermatica interna; gerade dieses Gefäß gewährleistet diesem Nerven eine längere Lebensdauer nach Ligatur der Aorta, die, wie oben schon gesagt, jedesmal 
unterhalb der Abgangsstelle der Art. renalis, der die linke Art. spermatica int. entspringt, statthatte. - Die Muskulatur der hinteren Extremitäten ist gleichfalls nicht ganz außer Ernährung gesetzt, das besagt für einzelne Muskelgruppen die objektiv leicht festzustellende günstige Gefäßversorgung und für die Extremität überhaupt der Nachweis einer zuerst 2 Stunden nach Ligatur sich einstellenden, dann dauernd - mitunter ad maximum zunehmenden Injektion der Hautvenen, sowie das oft stärker ausgeprägte interstitielle Ödem. Bei Obduktion erwiesen sich daneben jedesmal auch die Beckenvenen von flüssigem Blute strotzend gefüllt. Die Vena cava, die bald nach Aortenligatur zusehends kollabierte, zeigte fast ausnahmslos einen normalen Füllungszustand. Gleichwohl war die Blutzufuhr im allgemeinen zu schwach, um dem Muskel die Fähigkeit, auf direkt ihn treffende elektrische Reize zu reagieren, für eine längere Zeit noch zu erhalten, aber immerhin noch ausgiebig genug, um seine Kontraktionsfähigkeit überhaupt, wenigstens noch so lange zu konservieren, als eine Übermittlung des elektrischen Reizes auf dem Wege seines besser ernährten, deshalb lebendfrischeren, motorischen Nervens möglich war. In diesem Falle war also wegen der interfibrillären Endauffaserung der motorischen Nervenfäden die Übermittlung des elektrischen Reizes energischer, der Effekt prompter, als bei direkter Applikation, die oben definierte spezifische Muskelirritabilität gleichwohl - auch wenn der direkte, nicht über den Nerven geschickte Reiz makroskopisch erfolglos blieb - erhalten, das beweisen die nach Sistierung der Erregbarkeit und des Leitungsvermögens der Nerven noch gewonnenen posttraumatischen Kontraktionsbilder (Wülste und Ringe).

Bei Annahme einer totalen arteriellen Muskelanämie hätte nach Ablauf von 3-4 Stunden auch der maximale über einen noch funktionstüchtigen Nerven geschickte Reizimpuls keine Muskelkontraktion mehr auslösen können, das besagt folgender Versuch :

Bei einem Kaninchen werden direkt im Anschluß an die Aortenligierung beiderseits die Art. femoralis, epigastrica superficialis et inferior sowie die Art. obturatoria unterbunden, damit also die Kollateralwege verschlossen; die peripheren, motorischen Nerven ( $N$. ischiadicus, femoralis und obturatorius) blieben verschont. $3^{1 / 2}$ Stunde 
später waren bei maximaler direkter und indirekter Reizung keine Muskelkontraktionen mehr nachweisbar, eine nennenswerte Injektion des venösen Gefäßnetzes fehlte. Nach einer weiteren Stunde befanden sich die hinteren Extremitäten im Starrezustande, die Muskeln waren fest, die einzelnen Glieder in leichter Flexion kontrakturiert; die Muskelstarre bestand noch kurz vor dem Tode des Versuchs tieres ( 17 Stunden post operationem).

Auf Seite $32 \mathrm{I}$ berichteten wir von einem leichten postmortalen Starrezustand, der schon vor definitivem Erlöschen der elektrischen Erregbarkeit der Muskeln in Erscheinung trat; bei Durchmusterung unserer letzten Protokolle wird man ausnahmslos, falls nicht neben der Aortenligatur noch anderweitige Unterbindungen gemacht wurden, die Aufzeichnung wiederfinden, daß die Muskeln der hinteren Extremitäten und der Gesäßgegend $4-41 / 2-5$ Stunden nach Operation in einen mehr oder weniger ausgeprägten Starrezustand verfielen, der in einzelnen Fällen dem Bilde der definitiven Starreverkürzung außerordentlich nahekam; bei einigen Tieren stellte sich nach Eintritt der Extremitätenstarre der Schwanz in extreme Dorsalflexion. Daß diese Starre noch nicht als ein definitiver Zustand zu deuten ist, erhellt aus dem auf Seite 333 mitgeteilten Ergebnisse, wonach mit Eröffnung des Aortenstromes trotz schon bestehender Muskelkontraktur wieder eine Restitutio ad integrum eingeleitet wurde; die Annahme, daß diese Kontrakturen mehr zentraler, spastischer Natur seien, ist widerlegt durch die Feststellung der Permanenz dieses Zustandes nach Durchtrennung der motorischen Extremitätennerven. Bei Vergleich dieser Erscheinungen mit den Folgezuständen nach künstlich geschaffener, totaler, arterieller Anämie (s. den letzten Fall), gibt die frühere Feststellung einer, wenn auch nur geringen Zirkulation in dem scheinbar durch die Aortenligatur außer Ernährung gesetzten Gebiete wohl die richtige Erklärung für die längere Hintanhaltung des Eintritts der definitiven Starre.

Den Schluß dieses Kapitels bildete die Untersuchung der Frage, ob und inwieweit sich im Bereiche des anämisierten Gebietes nach Eintritt und bestimmter Dauer der manifesten Starre mit Eröffnung des arteriellen Kreislaufs Restitutionsvorgänge einstellen.

Bei einem Kaninchen werden die Aorta, die Art. epigastrica et obturatoria unterbunden, die Art. femoralis aber geschont; gleichfalls 
die Oberschenkelnerven freigelegt und unterhalb ihrer Austrittsstellen aus dem Becken in ca. I $\mathrm{cm}$ Ausdehnung ihres Gefäßüberzuges entkleidet. Vier Stunden später waren die hinteren Extremitäten starr, gegenüber dem elektrischen direkt und indirekt applizierten Strom reaktionslos; nach ca. dreistündiger Dauer dieses Starrezustandes wird die Aortenligatur wieder gelöst; wie mit einem. Schlage ist die Starre wieder verschwunden. Die Hautgefäße vordem kolla. biert, sind spontan extrem injiziert; die helle transparente Haut der Hinterbeine erscheint durch starke reaktive Hyperämie hellrot; nach 16 Tagen war die erste leichte Kontraktion bei direkter Reizung nachweisbar; die ersten aktiven Bewegungen konnte ich erst nach sieben Wochen feststellen, zu gleicher Zeit bestand Zehengangrän, über beiden Fersen waren ausgedehnte Dekubitalgeschwüre; der Femoralis. puls war bis zur Kniekehle beiderseits palpabel.

Einen diesem Versuchsergebnisse ähnlichen Effekt erzielten wir dadurch, daß wir mittels eines dünnen Gummischlauches den Oberschenkel des Kaninchens an der Grenze des mittleren zum unteren Drittel fest abschnürten und die Schnürung jedesmal sieben Stunden liegen ließen. Wenn auch unter der äußerst kräftigen Druckwirkung des Schlauches sämtliche Weichteile derart den Knochen angepreßt waren, daß nach Lösung desselben eine tiefe Schnürfurche sichtbar, dadurch die Garantie eines völligen Abschlusses der Weichteilgefäße garantiert war, dann blieb trotzdem noch ein Weg offen, auf welchem dem unterhalb der Ligaturebene gelegenen Extremitätenabschnitte Blut wieder zugeführt werden konnte; es handelt sich um die oberhalb der Schnürfurche in den Femur eintretenden Vasa nutritia; innerhalb dieser sieben Stunden wurde doch so viel Blut peripherwärts geleitet, daß der Unterschenkel fast ausnahmslos leicht geschwollen und das Hautvenennetz schließlich stark injiziert erschien. Zum Unterschiede von dem allmählichen Eintritt der die Glieder in Flexionsstellung überführenden Kontraktur nach Aortenunterbindung stellten sich in vorliegendem Falle Unterschenkel und Fuß schon während der Umschnürung des Oberschenkels in extreme Extension - in diesem Zustande bildeten Ober-, Unterschenkel und FuB ungefähr eine Gerade -; nur durch gewaltsames Redressement konnten die einzelnen Glieder in Flexionsstellung gebracht werden. Die Ursache dieser spontan auftretenden Streckstellung ist weniger - vgl. unsere bisherigen Deduktionen - in organisch-chemischen Veränderungen der Muskelfaser als vielmehr in rein mechanischen Momenten $\mathrm{zu}$ suchen. Durch die feste Umschnürung wird der Muskel am Orte der Läsion auf ein Minimum seines ursprünglichen Querschnitts zusammengepreßt; die Preßwirkung löst gleichzeitig Zugspannungen aus, die ihrerseits nur durch stärkere Annäherung der Muskelenden einen gewissen Ausgleich erfahren können. Von den dem Femur angelagerten Muskeln zeigt der M. quadriceps bei weitem den größten 
Querschnitt, eine Tatsache, die den prävalierenden Spannungseffekt des Streckmuskels gegenüber dem der Nachbarmuskeln u. E. erschöpfend erklärt. Auf gleichfalls rein mechanische Momente ist die Streckstellung des Fußes zurückzuführen; außer der Spannung im Bereiche der Fußbeuger registrieren wir noch die von dieser wieder abhängigen Zugspannung der Fußstreckmuskeln. Letztere Feststellung ist deshalb von besonderer Wichtigkeit, weil wir nämlich bei nachfolgender mikroskopischer Untersuchung der Unterschenkelmuskeln jedesmal und tast ausschließlich nur in solchen Muskeln, die neben dem ischämischen Einflusse ähnliche Spannungswirkungen erfahren hatten, spezifische Muskelfaserveränderungen nachweisen konnten, die ihrerseits wieder je nach dem Entnahmetermin - ob früher oder später nach Abnahme des Schnürschlauches - außer den bisher schon mehrfach erwähnten Typen (Kontraktionswülsten) -beispielsweise nach länger dauernder Einwirkung des reaktiven Gewebsödems: die schönsten Bilder des hyalinen Faserzerfalls darboten - einen für die Erklärung der hyalinen Degeneration der Muskelfaser überhaupt, wichtige Beobachtung.

In den Fällen, in denen wir willkürlich die durch die Unterbindung der Aorta anämisierten Unterschenkelmuskeln kurze Zeit nach Ligatur durch Schnitt oder Quetschung insultierten, konnten wir - nach Lösung der Ligatur - ähnliche Faserveränderungen nachweisen; die Präparate von Muskeln, die nicht derart nachbehandelt wurden, zeigten dagegen auch nicht im entferntesten diesen Zerfallsbildern ähnliche Degenerationsprodukte. Wenn wir sonst noch ein von den oben skizzierten, nach Unterbindung der Aorta gewonnenen Beobachtungsbildern etwas abweichendes Untersuchungsergebnis nennen sollen, so dieses, daß völlige Sistierung der Muskelerregbarkeit gegenüber dem faradischen Strome gemeiniglich frühzeitiger, durchschnittlich $3-61 / 2$ Stunden nach Abschnürung auftrat; in der durch die Quetschung und Ischämie verursachten stärkeren Alteration des Nervus ischiadicus und femoralis liegt wohl in erster Linie die Ursache.

Das Moment des Eintritts einer eigentlichen Muskelstarre war wegen der von vornherein bestehenden starken Muskelspannung naturgemäß schwer zu fixieren; von der Erwägung ausgehend, daß jeder lebende, auch der gelähmte, aber gespannte Muskel im Moment der Durchtrennung in seinen Schnittenden zurückschnellen muß, machten wir entsprechende Versuche und konnten feststellen, daß nach Erlöschen der faradischen Erregbar- 
keit eine ähnliche Reaktion nicht mehr auslösbar, mithin an einen durch Myosingerinnung verursachten Dauerzustand - an den Eintritt der Muskelstarre - zu denken war. Unmittelbar nach Abnahme des Schnürschlauches erschlaffte - ähnlich wie nach Lösung der Aortenligatur - die vordem straffe Unterschenkelmuskulatur wieder zusehends; spontan setzte eine starke Hyperämie ein; die in kurzer Zeit sich dann entwickelnde, oft enorme Schwellung verdankte einem vermehrten Afflux arteriellen Blutes, vor allem aber einer stärkeren Zirkulationsbehinderung im Bereiche des venösen Kreislaufes ihre Entstehung; sie war der sinnfällige Ausdruck der tiefgreifenden toxischen und mechanischen Gefäßschädigung; die insuffiziente Zirkulation im venösen System, die Stasis ganz allgemein wurde nicht zuletzt noch begünstigt durch die vorübergehende Muskelparalyse. Das sekundäre Weichteilödem war oft derart intensiv, daß schon $6-9$ Stunden nach Lösung des Schlauches die vordem scharf ausgeprägte tiefe Schnürfurche ausgeglichen erschien. Die Schwellung schwand in den einzelnen Fällen nach 20-38 Tagen; einen früheren Termin konnte ich im Gegensatze zu Heidelberg, der den 5.-8. Tag nennt, keinmal notieren. Derselbe Autor schreibt, daß nach I 4 Tagen die Extremität wieder aktiv gebraucht werde - gewiß, soweit die Funktion der Oberschenkelmuskeln in Betracht kommt --, die ersten aktiven Bewegungen der Muskeln des Unterschenkels konnte ich in den von mir beobachteten Fällen frühestens 3o Tage nach dem Abschnürungsversuche einwandfrei feststellen. Weshalb wir die Anämie nach Ligatur der Aorta sowie in den letztgeschilderten Versuchen gerade 7 Stunden einwirken ließen? Weil durch die Untersuchungen $\mathrm{Heidelbergs}$ festgelegt worden ist, daß eine 7-8 stündige Unterbrechung des Kreislaufs genügt, um ebenso, wie beispielsweise eine 24 stündige dauernde Ligatur, die Muskeln totenstarr zu machen, um aber auch nach Lösung intensive Entzündungserscheinungen eintreten zu lassen, ein Effekt, auf den wir bei Besprechung unserer, während des Studiums der ischämischen Muskelkontrakturen experimentell gewonnenen Ergebnisse noch einmal zurückzukommen haben. Die Restitution der Extremität ist die Regel, der Eintritt einer Gangrän eine seltene Ausnahme.

Der Besprechung einer im Anschlusse an Zirkulationsunter- 
brechung entstehenden Lähmung und Starre glaubten wir in Würdigung der besonderen Bedeutung, die gerade diese Reaktion für die Erkenntnis der ischämischen Myositis hat, einen breiteren Raum gewähren zu müssen.

Bisher vermieden wir, wenn anders es nicht unumgänglich notwendig war, auf die feinen Muskelfaserveränderungen als Folgen der Einwirkung länger dauernder Ischämie bzw. $\mathrm{CO}_{2}{ }^{-}$ Intoxikation ausführlicher einzugehen. Es erschien uns vorteilhafter, dieselben in einer Folge, im Zusammenhange mit der Schilderung sonstiger dieses Kapitel berührender Degenerationserscheinungen abzuhandeln.

Etwas längere Zeit werden wir bei der Untersuchung der hyalinen Faserentartung zu verweilen haben; dieser eigenartige Degenerationsprozeß, der außerordentlich häufig in den verschiedensten Präparaten von uns aufgedeckt wurde, ist zu interessant, als daß man ihn nur mit kurzen Worten abtun, und zu stark diskutiert, als daß man von vornherein der Überzeugung leben könnte, in ihm ein abgeschlossenes, längst erledigtes Kapitel der Pathologie des quergestreiften Muskels vor sich zu haben. Die ausführlichen Besprechungen und lebhaften Kontroversen, die der Arbeit Zenkers : ,Über die Veränderungen der willkürlichen Muskeln im Typhus abdominalis, Leipzig I 864 ", folgten, haben meiner Auffassung nach auch in Wirklichkeit keine erschöpfende und allgemein befriedigende Erklärung gezeitigt. Neuerdings wurde wieder durch die von uns oben schon zitierten eingehenden Untersuchungen Thomas die Frage nach Wesen und Bedeutung dieses Prozesses wieder aufgerollt.

Die Fragestellung, um die sich damals die Diskussionen bewegten, lautete etwa folgendermaßen: Ist die hyaline oder wachsartige Degeneration eine rein postmortale Erscheinung, oder ist sic auch schon intra vitam nachweisbar, beruht sie auf einer spontanen Gerinnung der kontraktilen Substanz und ist sie daher ein der Leichenstarre ähnlicher, wenn nicht mit ihr identischer Prozeß? Man fragte sich, ob eine rein physikalische Erklärung zulässig, ob dieselbe auf Zerreißung und Retraktion der Muskelprimitivfibrillen zurückzuführen sei. Man konstatierte sie schließlich bei fast allen fieberhaften Erkrankungen und nannte neben 
Typhus vor allem Cholera, Puerperalsepsis, Miliartuberkulose, Gelenkrheumatismus, Scarlatina, unter anderem auch Tetanus und Trichinosis; man beobachtete die hyaline Degeneration an Muskelfasern nach Verletzungen sowie in der Umgebung maligner Geschwülste.

Aus den oben gemachten kurzen Andeutungen erhellt schon zur Genüge die allgemein unklare Vorstellung, die die einzelnen Autoren von diesem Prozesse hatten. In der Definition der äußeren Erscheinungsform war man freilich sich bald einig. Man stellte fest, daß die quergestreifte kontraktile Fasersubstanz sich in homogene, wachsglänzende Klumpen verwandele, die die seltsamsten, häufig zylindrischen Formen annehmen konnten; mitunter gelang es, mit stärkeren Systemen in den glänzenden Pfröpfen feinste Querstreifung noch nachzuweisen; die hyalinen Massen - so schrieb man weiter - dehnen infolge stärkeren Volumens den Sarkolemmschlauch aus, zwischen den Pfröpfen ist derselbe kollabiert; die Pfröpfe sind weiter noch durch mehr oder weniger zahlreiche Einrisse ausgezeichnet.

Neben dieser Zerfallsform beschrieb Zenker noch einen anderen Typ; die körnige Degeneration. Diese betrachtete er gleichsam als Vorstufe der wachsartigen Faserveränderung. Als erste Entstehungsursache überhaupt bezeichnet er die Aufnahme neuer Stoffe in die kontraktile Substanz: bei langsamem Vordringen eines dazu noch spärlichen Materials lagere dasselbe sich in Körnchenform zwischen die Primitivfibrillen, bei schnellerer Invasion gelange es in die Muskelelemente selbst, ein Akt, der dann das charakteristische wachsartige Aussehen der affizierten Muskelfasern bedinge.

W eihl, der den Versuch machte, auf experimentellem Wege über das eigentliche Wesen der hyalinen Faserdegeneration Klarheit zu erhalten, kommt zu der Schlubfolgerung, daß es durch Eingriffe der verschiedensten Art gelänge, an der Zungenmuskulatur des Frosches Veränderungen hervorzurufen, die mit der wachsartigen Degeneration die größte Ähnlichkeit hätten, womöglich mit ihr identisch seien. „Dadurch, da $\beta$ man diese Veränderungen willkürlich und zwar momentan hervorrufen kann, ist bewiesen, daß sie weder den Charakter einer Degeneration noch den einer Entzündung tragen; sie beruhen höchstwahrscheinlich auf einer Gerinnung der kontraktilen Muskelsubstanz. Der bisher übliche Name ,,wachsartige Degeneration" sei deshalb durchaus nicht zutreffend und etwa durch die von N eumann vorgeschlagene Bezeichnung: ,schollige Zerklüftung" zu ersetzen." 
E r b fand die sogenannte wachsartige Veränderung jedesmal nach Verletzung der Muskeln; für die Entwicklung des Prozesses erschien es gleichgültig, ob die Muskeln nach der Verletzung in dem lebenden Körper blieben, oder aus demselben entfernt wurden. Er definiert denselben dann schließlich als die Folge eines der Totenstarre ähnlichen, wenn nicht ihr gleichen Gerinnungsvorganges. Dann gebe es auch pathologisch veränderte Muskeln, in welchen nach dem Tode auch in unverletzten Fasern dieselbe Veränderung eintrete eine Beobachtung, die er an Kaninchenmuskeln machte, deren Nerven einige Zeit vorher durchschnitten waren; nicht mehr definierbare chemische und molekuläre Veränderungen der Fasern seien wahrscheinlich die Ursache dieses Verhaltens; auch hier werde aber die Degeneration erst durch die Totenstarre hervorgerufen; dieselbe sei in diesen Fällen Leichenerscheinung. - Dieser Erklärungsversuch wird uns weiter unten - bei Mitteilung unserer eigenen Untersuchungsergebnisse noch einmal beschäftigen.

Popoff untersuchte die Veränderungen des Muskelgewebes bei Infektionskrankheiten in 28 Fällen. Als die häufigste Veränderung beobachtete er die körnige Metamorphose, d. h. die parenchymatöse Entzündung (Virchow) der Muskeln; er fand sie in sämtlichen Krankheitsfällen; daneben aber auch die Wachsmetamorphose in einem Krankheitsfalle stärker (Typhus abdominalis), in anderen weniger gut ausgeprägt. Auf die Tatsache, daß er diese pathologischen Veränderungen speziell im Diaphragma am ehesten ausgebildet und stets stärker ausgebreitet fand, möchten wir aus weiter unten noch zu besprechenden Gründen hingewiesen haben.

Die Polemik gegen $Z$ enker, der die hyalinen Veränderungen als einen rein degenerativen Prozeß betrachtet, wobei der Faserinhalt $=$ kontraktile Substanz plus Muskelkerne untergehe und der Ersatz der untergegangenen Muskelfasern aus den umliegenden Gewebselementen stattfinde - interessiert uns ganz besonders, da die Popoffsche Stellungnahme unsere Regenerationsstudien aufs engste berührt. P o p of f fand in manchen infektiösen Krankheitsformen fast stets, im übrigen sehr häufig Proliferationserscheinungen der Muskelfasern; sehr oft war der Vermehrungsprozeß in den körnig metamorphosierten, aber noch häufiger und in größerer Intensität in den wachsartig veränderten Fasern nachweisbar. An drei von ihm abgebildeten wachsartig veränderten, isolierten Fasern könne man leicht sehen, daß der Proliferationszustand nicht nur zwischen den wachsartig veränderten Massen der Muskelsubstanz, sondern innerhalb dieser selbst stattfinde. Dabei sähen diese Massen beim ersten Blick auf die gefärbten Präparate auch ganz gleichartig und homogen aus; nur bei Zerzupfung der Muskelfasern mit Nadeln und bei Isolierung könne man sich überzeugen, daß in diesen homogenen Massen eine große Anzahl von neugebildeten Muskelkernen eingeschlossen sei. 
Mitunter zeigten die Fasern cine partielle Anschwellung und Volumenzunahme, die vollständig einer homogenen, wachsartig degenerierten Masse ähnlich sehe. Beim Zerzupfen jedoch ließen diese Anschwellungen eine große Menge zelliger Elemente herausfallen; es erschien dann öfters die ganze Masse als ein Konglomerat dieser Elemente in wachsartig veränderter Muskelsubstanz. - Ein entsprechend instruktives Bild wird dargestellt.

P o p off beschreibt dann Präparate, die man als das Stadium der Entwicklung der wachsartigen Veränderung ansehen könne, unter anderem eine Muskelfaser, deren Querstreifen einander derart genähert und so zart seien, da $B$ man sie nur noch bei Anwendung starker Vergrößerung nachweisen könne; gleichzeitig sei bei verschiedener Einstellung des Focus die Muskelkernwucherung eine sehr ausgesprochene, somit als nicht dem Sarcolemma zugehörig zu betrachten. Um weitere Gewißheit über seine Ansicht zu erhalten, daß die wachsartig veränderten Muskelfasern entgegen der Auffassung $Z$ enkers nicht als Caput mortuum zu betrachten seien, wurde der Proze $B$ auch an Querschnitten studiert; die. Untersuchungsergebnisse stimmten mit den an Längsschnitten gewonnenen Resultaten vollkommen überein. So fand er, daß Kerne, die in Teilung begriffen waren, nicht nur zwischen den hyalinen Klumpen, sondern auch in denselben lagen, sowie ihr Vorhandensein in Fasern, die keinen eigentlichen Zerfall der Muskelsubstanz zeigten und aus ganz ununterbrochenen glänzenden Massen bestanden. Bei Typhus abdominalis sah $\mathrm{P}$ o p of $\mathrm{f}$ nicht selten den ganzen Inhalt der "Muskelprimitivbündel" in einzelne Muskelkörperchen zerfallen (d. h. die einzelnen Kerne wie von einer Protoplasmaschicht umgeben). Die Elemente, die sich bei der wachsartigen Degeneration der Primitivmuskelfasern entwickeln, sind nach Popoffs Ansicht entweder Bildungen, welche ihrer Form und Größe nach vollständig ähnlich sind den Muskelkernen mit einem oder zwei Kernkörperchen und mit mehr oder weniger körnigem Inhalte, oder es sind Bildungen, welche denselben Charakter haben und etwas größer sind; dabei kann auch ihre Form infolge sehr starker Vermehrung und Anhäufung der Elemente eine sehr verschiedene sein. Sie enthalten schließlich nicht selten 2 bis 3 Kerne mit Kernkörperchen und erreichen zuweilen eine ganz bedeutende Größe.

Nach Popoffs Ansicht ist die wachsartige Veränderung weniger als ein Degenerations- als vielmehr als ein Proliferationsproze $B$ zu betrachten. Er nimmt an, daß die in den Muskelfasern neugebildeten Elemente nicht ausschließlich dem Untergang verfallen sind, wie Waldeyer behauptete, daß sie vielmehr auch aus sich heraus neue Fasern bilden könnten.

Bemerkenswert erscheinen uns noch die Untersuchungen der Vorgänge im Bereiche des die Muskelfasern umschließenden Bindegewebes 
während der Entwicklung der hyalinen Faserdegeneration. P op of $f$ kommt zu dem Schlusse, daß die Gleichzeitigkeit und Gleichartigkeit der entzündlichen Veränderungen in den Muskelfasern und dem zugehörigen Bindegewebe, wie sie in der Regel bei typhösen Krankheiten beobachtet würden, für eine Ursache sprächen, die in einer und derselben Zeit die Erscheinungen in beiden Geweben hervorrufe. $\mathrm{P}$ o p off wendet sich gegen die mechanische Theorie $\mathrm{W}$ ald eyers, die zur Erklärung des wachsartigen Glanzes - bedingt durch stärkste Annäherung der Querstreifen - kräftige Muskelkontraktionen zitierte; danach müßte die wachsartige Veränderung der Muskelfasern hauptsächlich bei solchen Krankheiten angetroffen werden, die mit sehr lebhaften Krämpfen einhergingen: Lyssa, Tetanus, Cholera, StrychninVergiftung, und dieselbe bei Krankheiten wie Typhus, wo Krämpfe wohl kaum je zur Beobachtung kämen, entweder gar nicht oder doch nur in geringem Grade vorhanden sein; alles das verhielt sich in der Tat ganz umgekehrt. Die Anwesenheit dieser Veränderungen bei traumatischer Entzündung des Muskelgewebes oder bei anderen Entzündungsprozessen, gleichviel, ob durch chemische oder mechanische Reizung zustande gebracht, stünden ebenfalls im Widerspruch mit der mechanischen Erklärung der betreffenden Veränderungen, worauf Waldeyer seine Theorie stützte. Für die Annahme eines noch während des Lebens stattfindenden Gerinnungsprozesses in den Muskalfasern, auf den Waldeyer auch als erklärendes Moment hinweist, fehlter noch hinlängliche Beweise. Diesen Erklärungsversuchen gegenüber, die beide u. E. einen richtigen Kern bergen, halte ich die Auffassung $P$ op of f s zum mindesten für gewagt; nach ihm entsteht die Annäherung der Querstreifen aneinander dadurch, daß die Muskelpartikelchen, die zuvor in dem Muskelschlauch eine größere Entfernung voneinander hatten, durch die starke Kernwucherung sich einander mehr und mehr nähern, und die ganze Muskelfaser breiter machen, als sie im normalen Zustande ist. Aus einer oben schon zitierten Arbeit $\mathrm{Heidelbergs}$ möchte ich an dieser Stelle noch einen Passus erwähnen, dem wir bis auf einen Punkt völlig beipflichten können. Dieser Autor untersuchte den M. extensor digitorum des Kaninchens 2-3 Tage nach dem Wiedereintritt der Zirkulation, die 24 Stunden lang - in unseren Versuchen, wie früher erwähnt, nur sieben Stunden lang - durch elastische Umschnürung des Oberschenkels dicht oberhalb des Kniegelenkes unterbrochen wurde und stellte fest, daß die Muskelkerne numerisch außerordentlich reduziert waren; die vorhandenen hatten ihr sukkulentes Aussehen verloren; sie waren geschrumpft und krümelig, intensiv blauschwarz mit Hämatoxylin gefärbt; eine bedeutende Menge kleiner, stark gefärbter Körperchen manifestierte sich deutlich als der Rest der Abkömmlinge der Kerne; die eigentliche Muskelsubstanz erschien eigentümlich körnig, opak bei übrigens deutlicher Querstreifung; sie hatten die 
Neigung, in gewissen Abständen genau in der Richtung der Bow $m$ anschen Discs etwas auseinanderzuweichen; wachsartige Degeneration hat $\mathrm{Heidelberg}$ nur sehr selten und ganz vereinzelt gesehen. Ich halte es aus oben schon angedeuteten, weiter unten noch genauer zu besprechenden Gründen nicht für einen blinden $\mathrm{Zu}$ fall, dab wir neben dem M. gastrocnemius gerade diesen Muskel als besonderen Fundort degenerierter Muskelfasern bezeichnen konnten. Auf Seite 327, bei Besprechung des schließlichen Schicksals eines isolierten, aber im Körper verbliebenen Muskels streiften wir kurz die Erklärung für den krümeligen Kernzerfall. Schon $\mathrm{H}$ eidelberg hatte diese Frage, die für die Beurteilung der ischämischen Muskelveränderungen im allgemeinen von nicht $\mathrm{zu}$ unterschätzender Bedeutung ist, in bestem Sinne erledigt. Schaltet man eine Extremität längere Zeit aus dem Blutkreislauf aus, so gilt sie schließlich - je nach Dauer der Zirkulationsunterbrechung in allen Teilen als tot. Nach Abtötung des Tieres ergibt die mikroskopische Untersuchung der so geschädigten Muskeln Bilder, die sich auffallend von denen der nicht geschädigten Muskeln unterscheiden. Als notwendigen Faktor für den Zerfall und Schwund der Muskelkerne ergibt sich somit die im konkreten Falle nach Lösung der Ligatur einsetzende Durchspuilung der Muskeln mit Blut und Lymphe. „Die Kerne sterben durch die tiefe Alteration einer längeren Zirkulationsunterbrechung ab und erliegen nun einem AuflösungsprozeB in der Lymphe, und, indem sich einige Partien leichter lösen als andere, bleiben krümelige Reste zurück, die dann gleichfalls in der Körperflüssigkeit verschwinden." Je nach Dauer der Zirkulationsunterbrechung ist der Schwund der Muskelkerne universell oder nur partiell. Untersucht man einen Muskel vielleicht drei Tage nach Lösung einer siebenstündigen Ligatur, dann wird man mitten unter den Kernfragmenten hier und da noch wohlerhaltene Muskelkerne tinden; durch eine Proliferation dieser Kerne wird dann der Muskelkernregenerationsproze $B$ in solchen Fällen eingeleitet. Die eingangs mitgeteilten Regenerationsstudien basieren zum großen Teil auf der Untersuchung dieser und ähnlicher Vorgänge.

Bei Besprechung der Muskelfasererregbarkeit haben wir mehrfach Nutzanwendung gemacht von Thomas Ansicht über die hyaline Muskelfaserveränderung. Zur genaueren Präzisierung derselben will ich die Hauptsätze, die Thoma bei Untersuchung der im Gefolge von Traumen auftretenden wachsartigen Umwandlungen der Muskelfasern (I. Mitteilung) notierte, kurz wiedergeben; die Frage, ob diese Auffassung verallgemeinerungsfähig ist, d. h. ob sie auch die Erklärung für die Entstehung der nicht traumatischen, beispielsweise posttyphösen Form gibt, wird am 
Schlusse dieses Kapitels noch besprochen werden unter Anführung auch eigener experimenteller Beobachtungen.

Thoma untersuchte die Reaktion der lebenden Zungenmuskelfaser des curaresierten Frosches auf die direkte, durch eine feine Nadel unter dem Mikroskop gesetzte Verletzung. Nach seinen Beobachtungen ruft die Verletzung zunächst eine initiale, idiomuskuläre Kontraktion hervor, welche umschriebene, bauchförmige Verdickungen der Muskelfasern erzeugt. Diese initialen Kontraktionen können, vorausgesetzt, daß die Verletzung selbst keine Kontinuitätstrennung des Sarkolemmainhaltes bewirkte, wieder verschwinden, wenn der gesetzte Reiz abklingt, indem die Spannung der Muskelfasern den alten Gleichgewichtszustand der einfachbrechenden und der doppeltbrechenden Teile wiederherstellt. Zumeist führt jedoch das Trauma entweder unmittelbar oder durch die von ihm hervorgerufene idiomuskuläre Kontraktion zu einer Kontinuitätstrennung des Sarkolemmainhaltes. Im ersten Falle kann man von einer direkten traumatischen Kontinuitätstrennung des Sarkolemmainhaltes sprechen; im zweiten Falle aber liegt eine Selbstzerreißung der Muskelfaser vor; Hand in Hand mit diesen Vorgängen entwickeln sich die wachsartig glänzenden Wülste. Dadurch, daß die Rißenden des Sarkolemmainhaltes infolge Kontinuitätstrennung von einem großen Teil der Zugwirkung, welche Folge der Längsspannung der Muskeln ist, entlastet werden, ist die idiomuskuläre Kontraktion in der Lage, hier in beschränkter Ausdehnung eine maximale Verkürzung des Sarkolemmainhaltes herbeizuführen. Demgemä $B$ ziehen sich die Rißenden des Sarkolemmainhaltes, soweit sie völlig entspannt sind, maximal zusammen. Mann kann daher die auf diesem Wege entstandenen wachsglänzenden Wülste auch als maximal kontrahierte Wülste bezeichnen. Ähnliche maximale Kontraktionen können in entspannten oder sehr schwach gespannten Muskelfasern auch durch verschiedenartige lokale mechanische oder chemische Reizungen erzeugt werden, ohne daß eine Kontinuitätstrennung des Sarkolemmainhaltes auftritt. Sie stellen sich dann als wachsglänzende, quer oder schräg über die Muskelfasern ziehende Bänder dar. Längeren Bestand können jedoch die maximal kontrahierten Bänder nur dann gewinnen, wenn bei vollständig aufgehobener Längsspannung jede Kraft fehlt, welche nach Ablauf der Reizwirkung die maximal kontrahierten Muskelfaserabschnitte wieder auf ihre normale Länge zu dehnen imstande wäre. Bei der Kontinuitätstrennung des lebenden Sarkolemmainhaltes bleiben die wachsartig glänzenden, maximal kontrahierten Wülste dauernd bestehen, weil infolge der Kontniuitätstrennung die Kraft, welche imstande wäre, dieselbe wieder zu dehnen, eben nicht einwirken kann. Die wachsähnlich glänzenden Wülste bleiben in seltenen Fällen dicht nebeneinander liegen; in der Regel weichen dieselben eine Strecke weit auseinander; diese Ortsveränderung verlangsamt sich früher oder 
später; schließlich bleiben die maximal kontrahierten Wülste unverrückt an ihrem neuen Orte liegen, der zuweilen, keineswegs aber immer sehr weit von der Läsionsstelle entfernt ist. - Um die gleiche Zeit etwa. treten weitere Veränderungen auf, die ihrer äußeren Erscheinung nach erheblich von der Wulstbildung verschieden zu sein scheinen. Zunächst bemerkt man in den an die maximal kontrahierten Wülste angrenzenden Teilen der kontraktilen Substanz das Erscheinen glänzender Körner. Zu den Körnungen gesellen sich dann kleine Spalten und diese nehmen ziemlich rasch an Zahl zu, indem sich die kontraktile Substanz zugleich verjüngt und von der Sarkolemmascheide ablöst. Die nunmehr entstandenen körnigen Massen erscheinen in der Regel, wenngleich nicht immer, in Querscheiben geordnet, zwischen denen Querspalten sichtbar sind. Es ist damit eine Veränderung gegeben, welcher als diskoider Zerfall bezeichnet werden kann. Dieser Zerfall stellt nach T h o m a nur eine Modifikation der Vorgänge dar, welche die maximal kontrahierten Wülste erzeugen. Die durch die maximale Kontraktion, welche die glänzenden Ringwülste erzeugt, hervorgerufenen Querspalten ergeben, wie es scheint, den Reiz, der die angrenzenden Teile des Sarkolemmainhaltes zur Kontraktion anregt. Diese Kontraktion führt, weil die Spalten zugleich den Sarkolemmainhalt entspannen, zu einer maximalen Verkürzung der abgespaltenen Teile desselben. Die später entstandenen diskoiden Ringwülste sind kleiner, weil sie sich außerhalb des Gebietes der von dem Trauma direkt angeregten idiomuskulären Kontraktion entwickeln. Die Körnung der diskoiden Massen dürfte Folge von kleinen Längs- und Querspalten sein, welche sich -- erstere zwischen, und letztere - in den Primitivfibrillen bilden. Außerdem wäre es immerhin möglich, da $B$ ein Teil dieser Körnungen feste oder halbflüssige körnige Zersetzungsprodukte des Sarkolemmainhaltes sind. Neben den, der Verletzung unmittelbar folgenden, maximal kontrahierten Wülsten, kann man häufig im Verlauf derselben Faser ähnliche größere Wülste, von $\mathrm{Th}$ o ma als sekundäre maximal kontrahierte Wülste bezeichnet, beobachten. Wenn sie zur Entwicklung gelangen, erscheinen sie immer in den noch wenig oder gar nicht veränderten Teilen des Sarkolemmainhaltes. Sie können längere Zeit stationär bleiben; zuweilen verschwinden sie wieder, indem die Kontraktion, der sie ihre Entstehung verdanken, nachläßt. In manchen Fällen tritt hinter diesen sekundären Wülsten von neuem der diskoide Zerfall auf; dann kann der Vorgang der Wulstbildung sich wiederholen, sodann maximal kontrahierte Wülste dritter, vierter und höherer Ordnung entstehen. Bei mehrfachen Verletzungen einer und derselben Muskelfaser entwickeln sich mehrere Paare von hyalinen Wülsten, an welche sich dann wie gewöhnlich die diskoide Zerklüftung anschließt. Letztere aber verschont unter Umständen einen Teil der intermediären, zwischen beiden Verletzungen gelegenen Strecken der Muskelfaser. In 
diesem Falle verkürzt sich die intermediäre Strecke erheblich unter gleichzeitiger Verbreiterung; sie zeigt eine wie es scheint mit Kontraktion verbundene Retraktion, indem sie zugleich eine undeutlich wachsartige Beschaffenheit annimmt.

Dies in kurzen Zügen der Inhalt Thomas erster Mitteilung, die, wie ersichtlich, die posttraumatischen Faserveränderungen in ihren ersten markanten Erscheinungen skizziert. Eine zweite Mitteilung orientiert über das weitere Schicksal dieses eigenartigen Faserkontraktionseffektes.

Thoma betont den besonderen Unterschied, den die Weiterentwicklung der bei Verletzungen entstehenden, wachsartig glänzenden, maximal kontrahierten Wülste zeigen, je nachdem diese Wülste sich von dem unverletzten Sarkolemmainhalte trennen, oder mit diesem im Zusammenhange bleiben. In letztem Falle behalten dieselben bis zum Schlusse der Regenerationsvorgänge die Eigenschaften der kontraktilen Muskelsubstanz; sie erweisen sich während dieser ganzen Zeit als stark doppelbrechend, zeigen jedoch keine Querstreifung; die silbergraue Färbung, das wachsartige Aussehen der Wülste bleibt bestehen. Durch die bei Wiederherstellung der Kontinuität und Rückkehr der Funktion wieder neu sich einstellende Zugspannung werden die verkürzten Teile der Primitivfibrillen wieder auf ihre normale, den wechselnden Spannungen entsprechende Länge gedehnt, damit die silbergraue Färbung, der wachsartige Glanz und die übrigen der maximal kontrahierten Muskelsubstanz zukommenden Eigenschaften beseitigt; die Querstreifung wird breiter, deshalb wieder erkennbar. Die maximal kontrahierten Wülste, welche sich von dem unverletzten Sarkolemmainhalte trennen, verlieren 9-27 Stunden nach der Verletzung ihre charakteristischen Eigenschaften; sie erfahren eine regressive Umwandlung in schließlich einfach hyaline Massen, in welchen jedoch die Muskelkörperchen erhalten bleiben. Die hyalin gewordenen Bestandteile der Wülste unterliegen weiterhin einer Aufquellung und Verflüssigung, durch welche die in denselben eingeschlossenen Muskelkörperchen frei werden. Die diskoiden Massen erleiden dieselbe regressive Metamorphose; sie verlieren vor allem verhältnismäßig rasch ihre Doppelbrechung und gehen dann allmählich in hyaline Substanzen über, die durch Quellung stark an Volumen zunehmen, schließlich verflüssigt und resorbiert werden. Bei Vergleich des geschilderten Kontraktionseffektes mit der bei Typhus abdominalis $z u$ beobachtenden wachsartigen Umwandlung der Muskelfasern ist eine gewisse Ähnlichkeit nicht zu verkennen.

In weiteren (in der 3. Mitteilung wiedergegebenen) experimentellen Untersuchungen, bemühte sich Thoma durch Ein. 
reihung eines neuen Momentes in seine bis dahin geübte Experimentaltechnik auch diese eigenartige Form der Zerklüftung naturgetreu zu gewinnen. Bisher wurden bei den Läsionsversuchen soweit als nur möglich Kreislaufsstörungen vermieden. Bei Verquickung der Faserläsion mit der künstlichen Schaffung von Zirkulations- d. h. Ernährungsstörungen erreichte Thoma den gewünschten Effekt.

Vorerwähnter Untersuchungsgang — auch bei Kaninchen praktisch durchführbar - interessierte uns deshalb ganz besonders, weil wir durch ihn auch noch einige Aufklärung über die Einwirkung der Ischämie auf die Muskelfasern zu erhalten hofften. Wir haben ihn eifrig durchgeprüft und Resultate erhalten, die, von einigen Abweichungen abgesehen, im Prinzipe mit den Beobachtungen Thomas übereinstimmen.

T h o m a versuchte durch Applikation des Induktionsstromes auf den isolierten überlebenden Musculus sartorius eine Selbstzerreißung desselben herbeizuführen. Der negative Ausfall dieses Experiments schließt nach ihm die Möglichkeit der Selbstzerreißung einer Muskelfaser überhaupt nicht aus, zumal wenn der Muskel in seiner Festigkeit durch Einwirkung irgendwelcher, wohl in erster Linie chemischer Insulte, geschädigt ist. Nach Injektion von salpetersaurem Silberoxyd in die Lymphgefäße der lebenden Froschzunge konnte er eine sehr große Zahl solcher Selbstzerreißungen, die ausnahmslos mit der Bildung maximal kontrahierter Wülste verbunden waren, beobachten. Über das interessante Ergebnis von Injektionsversuchen mit sterilem Terpentinöl, die von mir an den hinteren Extremitäten von $\mathrm{Ka}$ ninchen angestellt wurden und der Besprechung dieses Kapitels gewiß schon angeschlossen werden könnten, werde ich nicht ohne bestimmte Gründe erst gegen Schluß des ganzen Abschnittes berichten. Ein positives Ergebnis erzielte Thoma schließlich dadurch, daß er vor der Faradisierung den isolierten Musculus sartorius einkerbte. Bei nachfolgender Untersuchung der Schnitt- und Rißenden, der auf dem beschriebenen Wege in ihrer Kontinuität getrennten Muskelfasern, merkte er an ersteren wieder die typischen Kontraktionswülste; die Rißenden dagegen standen weit über die Reihen der durchschnittenen Fasern hervor, sie entbehrten dieser Wülste, waren quer abgestutzt, zuweilen etwas konisch verjüngt, stark längsstreifig; aus dieser Beobachtung schließt Thoma auf eine durch die starke Längsdehnung, die der Zerreißung vorangehe, bedingte Lähmung des Sarkolemmainhaltes; freilich betreffe dieser Zustand nur den der Rißfläche zunächst benachbarten Faserteil. Denn, wenn man den zerrissenen Muskel Io $\mathrm{mm}$ weit von der Rißfläche wieder durch- 
schneide, entstünden allseitig wieder die typischen Kontraktionswülste, während die Rißenden auch jetzt noch unverändert seien. Allerdings komme es vor, daß dieselben kurze Zeit nach der Zerreißung sich etwas verkürzten, zugleich dicker und stärker lichtbrechend würden; man erhalte dann das Bild eines ziemlich scharf begrenzten Kontraktionswulstes, der jedoch nirgendwo die typische Form der bei Durchschneidung auftretenden Wülste annehme. Thoma machte die Beobachtung, daB, wenn die Spannung in der Muskelfaser eine gewisse Höhe erreicht hatte, die Primitivfibrillen nacheinander abrissen, dabei deutlich als dünne und entsprechend der Querstreifung etwas punktierte Fäden hervortraten: nach der Zerreißung schlagen sich die Enden dieser Primitivfibrillen häufig haken- oder schlingenförmig um, während der noch mit den Nachbarfibrillen in Berührung stehende Teil derselben sich langsam zurückzieht, indem er an den Nachbarfibrillen hingleitet; dabei ist eine gegenseitige Adhärenz der Primitivfibrillen deutlich bemerkbar, während sie zugleich den deutlichen Eindruck selbständiger Gewebselemente hervorrufen.

Diese Schilderung kann ich Wort für Wort unterschreiben, nur erhielt ich den identischen Effekt an Muskelfasern, die erst eine gewisse Zeit nach Isolierung des Muskels zerrissen wurden. Wenn ich Thoma recht verstehe, machte er diese seine Beobachtungen an Fasern, die noch ein bestimmtes physiologisches Reaktionsvermögen besaßen, die auf die Querschnittsläsion mit der Bildung von Kontraktionswülsten antworteten. Nach meinen, an Kaninchenexperimenten gesammelten Erfahrungen ist mir kaum ein Fall bekannt, in dem es mir gelang, ähnliche Erfolge an den lebendfrischen, in Kochsalzlösung oder trocken untersuchten Faserpräparaten zu erzielen.

Ich verfuhr in der Weise, daß ich unter dem Mikroskop ein feines Faserzupfpräparat mit Hilfe zweier, flach geschliffener, in Holzstäbchen eingelassener, langer, gerader Nadeln, in der Richtung des Längsdurchmessers der Muskelfaser auseinanderzerrte; wohl kam es bei dieser Manipulation häufig genug zu einer Durchquetschung der Faser am Orte der eingreifenden Gewalt, aber auch ebensooft wurde der gewünschte Effekt erzielt: der Durchriß erfolgte fast ausnahmslos nahezu senkrecht zur Faserachse; die Rißenden waren stets gezackt und ausgefranst, eine fibrilläre Auffaserung in der oben beschriebenen Form war nicht zu erkennen; die vorstehenden Fransen erschienen deutlich quergestreift; in vereinzelten Fällen konnte man auch eine fibrilläre Zeichnung in denselben einwandsfrei feststellen. Mitunter schnurrten die Rißenden derart zusammen, daß man im ersten 
Momente maximale Kontraktionswuilste vor sich zu haben glaubte; bei schärferer Einstellung aber entpuppten sich dieselben als das Produkt einer räumlich begrenzten Aneinanderlagerung von Faserfalten, wie sie auch im ganzen Verlauf der Muskelfaser oft genug nachweisbar war. Durch leichte Auseinanderzerrung der Faser auf dem Objektträger konnte man mühelos die Faserfaltung wieder ausgleichen - freilich nicht immer: Denn innerhalb dieser Retraktionswülste traten mitunter doch noch regelmäßige, auf ähnliche Manipulationen dann nicht mehr reagierende Kontraktionswülste auf, wie sie sich überhaupt nahezu konstant im Bereiche sämtlicher Rißenden der lebendfrischen Muskelfaser kurz nach der Kontinuitätstrennung bildeten.

Eine Faserzerreißung im Sinne einer mikroskopisch deutlich sichtbaren Zerreißung der einzelnen, während der Überdehnung der Fasern sich voneinander loslösenden und aneinander vorbeigleitenden, quergestreiften Faserfibrillen erzielte ich in Muskelpräparaten, die erst mehrere Stunden nach Tod des Tieres, in einer Zeit, wo jegliche reaktive Faserkontraktion - als solche sind ja, wie schon gesagt, die Kontraktionswülste und -ringe schließlich zu definieren - als erloschen $z \mathrm{u}$ betrachten war, entnommen wurden; als frühesten Termin bezeichne ich den Eintritt der manifesten Muskelstarre (s. unsere früheren Ausführungen); es ist dann auch kein besonderes Kunststück, die in Kochsalzlösung suspendierten Muskelfasern unter dem Mikroskop in toto in ihre einzelnen Fibrillen zu zerlegen - nicht als ob dieser. Faserzustand ein untrügliches Charakteristikum für den Eintritt des Fasertodes wäre -- es müßte dann auch die oft hochgradige Dehiszenz der Muskelfaserfibrillen, wie ich sie bei Untersuchung stark ödematös durchtränkter oder durch Nervenresektion geschädigter Muskelin fand, als tot in rein funktionellem Sinne zu betrachten sein; dem widerspricht die klinische Beobachtung.

Kurze Zeit nach Bildung der Kontraktionswülste erschienen nach $\mathrm{T}$ h o m a neben diesen diskoide Zerklüftungen, die mehr oder weniger weit in den Muskel hineinreichten. Nach I8-24stündiger Konservierung des aufgespannten und zerrissenen Muskelpräparates unter Deckglas bemerkte $\mathrm{Thoma}$, daß die Muskelfasern zum Teil in rundliche und kurzzylindrische, wachsartig glänzende Segmente zerklüftet wurden, zwischen denen wieder diskoid zerklüfteter Sarkolemmainhalt und klare Flüssigkeit nachweisbar waren. Diese seine Erfahrungen zusammenfassend, deduziert er dann, daß die Querschnittsläsion als unerläßlicher Faktor für das Zustandekommen der maximal kontrahierten Wülste erst in Verbindung mit zunehmenden Ernährungsstörungen tiefere Wirkung zu erzeugen imstande ist; die bei dieser Voraussetzung über die Muskelfaser hinweglaufende, durch die Querschnittsläsion geschaffene Kontraktionswelle, die den Faserinhalt zerklüftet, findet schließlich ihr Ende, wenn sie entweder eine 
gewisse Strecke weit fortgeschritten ist, oder wenn durch die inzwischen eingetretene chemische Veränderung die Erregbarkeit des Sarkolemmainhaltes völlig erlischt. Dieser von $\mathrm{T}$ h o m a geschilderte endgültige Läsionseffekt war bei experimenteller Untersuchung des überlebenden Kaninchenmuskels frühzeitiger zu konstatieren.

Der einheitliche Läsionsvorgang - ob Durchschneidung oder Zerreißung - war von untergeordneter Bedeutung, die erste Reaktion war in beiden Fällen eben der maximal kontrahierte Wulst, dann aber setzte schon nach Ablauf von 3-I2, spätestens nach 30 Minuten, die gleiche, oben beschriebene Faserzerklüftung ein; um diese Zeit herum war gewöhnlich der Läsionseffekt maximal. Ich habe in $1 / 4$ stündigen Intervallen den Kaninchenmuskel nach Abtötung des Tieres incidiert, sowohl den in Kochsalzlösung konservierten, als den trocken aufbewahrten Muskel; konnte dann feststellen, daß die Progredienz der Muskelfaserveränderung nach Ablauf der ersten halben Stunde auffallend schnell abnimmt; sehr bald beschränkt sich die Läsionswirkung auf das dem Insulte zunächst benachbarte Gebiet; sie tritt auf als Endwulst und sekundäre, grobkörnige, diskoide Zerklüftung; schließlich ist auch letztere nicht mehr vorhanden. Mit Auftreten des nur noch auf das Faserende beschränkten Kontraktionswulstes war jedesmal das Initialsymptom der dann kurz darauf einsetzenden allgemeinen Muskelstarre gegeben $(4-5$ Stunden post exitum). Die beschriebenen Faserveränderungen sind $\mathrm{m}$. E. das beste Charakteristikum einer noch bestehenden Lebensfähigkeit des betreffenden Faserindividuums, die unter gegebenen Bedingungen wohl noch groß genug ist, die Faserkerne auch nach schließlichem Aufbruch des Faserkörpers als fortpflanzungskräftig zu erhalten.

In einem zweiten Abschnitte untersuchte Thoma die Reaktion der lebenden Froschzunge auf den Druck einer Gummifadenligatur, die an der Grenze des hinteren zum mittleren Drittel angelegt wurde, die Weichteile völlig konstringierte, dadurch im peripheren Gebiete völlige Ischämie erzielte und verschieden lange Zeit liegen blieb.

Der auf diese Weise erzielte Effekt zeigte weitgehende Übereinstimmung mit dem an dem überlebenden Sartorius erhobenen Befunde. Der Ligaturdruck hat somit die Wirkung einer Querschnittsläsion; die Zerklüftungen und wachsartigen Umwandlungen stellten sich um so reichlicher ein, je mehr man sich der Ligaturstelle näherte. 
Die Muskelfasern sind im Bereiche des Ligaturbezirkes nicht zerklüftet, sondern in dünne, stark lichtbrechende Fäden verwandelt; die Querstreifung ist undeutlich oder stark verworfen. - Es handelte sich hier um eine Kompression der Muskelfaser durch den Druck der Ligatur, wobei zugleich ein paretischer Zustand des gedrückten Sarkolemmainhaltes eingetreten sei. - Segmentierungen aber fanden sich auch auf der proximalen Seite der Ligatur, weil, wie Thoma annimmt, der Ligaturdruck auch hier noch in gewisser Ausdehnung den Blutkreislauf geschädigt und unterbrochen habe.

Mit den im dritten Abschnitte mitgeteilten Untersuchungsergebnissen können wir wieder eigene Beobachtungen vergleichen. Thoma prüfte den Ligaturversuch auch an den hinteren Extremitäten des lebenden Frosches nach; wir experimentierten in dem gleichen Sinne an dem lebenden Kaninchen unter Bevorzugung jugendlicher Exemplare. $\mathrm{Ob}$ die Verschiedenheit mancherlei Muskelreaktionen, wie sie sich beim Vergleich unserer Untersuchungsergebnisse mit den Thomaschen Resultaten hie und da herausstellten, auf eine spezifische Rasseeigentümlichkeit der betreffenden Versuchstiere zu beziehen ist, lasse ich dahingestellt; die Möglichkeit ist nicht ohne weiteres von der Hand zu weisen. Thoma benützte zur Umschnürung des Oberschenkels 0,7-I mm dicke Gummifäden; wir ligierten mit einem vor Anlegung straff angezogenen, $4 \mathrm{~mm}$ dicken Gummischlauch und erreichten jedesmal durch 3-4 Touren bei entsprechender, tief bis zum Knochen greifender Muskelquetschung völligen Gefäßabschluß; im Interesse einer einheitlichen Angriffsrichtung der konstringierenden Gewalt und möglichst exakter Lokalisierung des Läsionseffektes gaben wir uns die größte Mühe, bei der Umschnürung die einzelnen Touren zur Deckung zu bringen, was uns auch fast ausnahmslos gelang. Die Schlauchenden wurden in der tief einschneidenden Ligaturfurche durch eine Arterienklemme aneinander fixiert, einer Lockerung der Umschnürung, wie sie sich bei den Versuchen die Schlauchenden zu knoten, wohl hätte einstellen können, dadurch wirksam vorgebeugt.

DaB durch diese elastische Umschnürung sämtliche Weichteile in besonderem Maße alteriert werden, bedarf keiner eigentlichen Betonung; die Muskeln sind oft genug, wie schon oben, bei Besprechung der Anämiewirkung, eine Vorbemerkung über diese Versuche besagte, auf ein Minimum ihres ursprünglichen 
Durchmessers reduziert. Der Nervus ischiadicus zeigte mehrfach bei der kurz nach Lösung der Ligatur vorgenommenen Isolierung tiefe Einkerbungen; in einem Falle war eine Intimaruptur der Art. femoralis mit nachfolgender Thrombosierung der Blutsäule des proximalen Gefäßabschnittes zu verzeichnen. Wenn man darauf ausgegangen wäre, einzig und allein die auf das Läsionsgebiet lokalisierten reaktiven Muskelfaserveränderungen zu untersuchen, dann hätte nach den am überlebenden Muskel gesammelten experimentellen Ergebnissen die Fragestellung nur schärfer präzisiert gelautet: Sind Trauma plus Zirkulationsstörung auch die wesentlichen ätiologischen Faktoren für die Entstehung der bisher beschriebenen Zerfallsformen im Muskel des noch lebenden Tieres? Die Frage, ob und inwieweit auch die durch das gleiche Trauma bedingte, in ungefähr die gleiche Ebene lokalisierte Nervenläsion von irgendwelcher, die beiden anderen Faktoren unterstützender Bedeutung sein konnte, tritt damit in den Hintergrund. Sie verdiente aber volle Berücksichtigung bei Beurteilung der degenerativen Faserveränderungen im Bereiche der von dem Trauma nicht direkt berührten Muskeln. Zur Erklärung der Veränderungen der Unterschenkelmuskulatur käme dann also nur noch die Zirkulationsstörung und die Insuffizienz bzw. völlige Unterbrechung der Nervenleitung in Betracht. Wir haben auch diese Frage schon oben gestreift bei Untersuchung der durch Oberschenkelumschnürung anämisierten Unterschenkelmuskulatur mit Hilfe des faradischen Stromes, und schon darauf hingewiesen, daß in ähnlichen Fällen die faradische Muskelerregbarkeit durchschnittlich $2^{1 / 2}-61 / 2$ Stunden nach Umschnürung erloschen war.

Wir sind dem Einwande, daß der Nervenläsion vielleicht doch eine besondere Bedeutung für die Erklärung der Muskelfaserdegeneration des peripheren, von der Umschnürung nicht direkt betroffenen Extremitätenabschnittes zukomme, dadurch begegnet, daß wir in zwei Fällen den Nervus ischiadicus sorgfältig unter besonderer Schonung seines Gefäßüberzuges isolierten, dann erst sämtliche Weichteile durch kräftig angezogene Seidenfäden ligierten. Daraufhin zeigten sich keine nennenswerten Verschiebungen der klinischen wie pathologisch-anatomischen Untersuchungsdaten; schlieBlich resezierten wir den N. femoralis, ischia- 
dicus und obturatorius in einer Ausdehnung von je $0,5 \mathrm{~cm}$ und umschnürten dann erst in der alten Weise den Oberschenkel; auch in diesen Fällen wurden 6 mal die für die Massenligatur typischen Degenerationsbilder aufgezeichnet.

Die spontan nach der Umschnürung des Kaninchenoberschenkels auftretende Streckstellung des Kniegelenkes und sekundäre extreme Plantarflexion des Fußes wurden in der schon mehrfach erwähnten Vorbesprechung eingehend gewürdigt; auch Tho ma berichtet bei Wiedergabe seiner nach Umschnürung gemachten Beobachtungen von einer extremen Streckstellung des Kniegelenks und Beschränkung der Exkursion des Fußgelenks; er weist die Annahme einer tonischen Kontraktion als Erklärung dieser auffallenden Erscheinung auf Grund von mechanischen Erwägungen, denen auch wir nachgegangen sind, zurück. Bemerkenswert erscheint mir das unterschiedliche physiologische Verhalten des Frosch- und Kaninchenmuskels bei Einwirkung der durch die Umschnürung geschaffenen Ischämie.

Th o m a schreibt, daß in den ersten Stunden nach Anlegung der Ligatur die direkte Erregbarkeit des gesunden und des ischämischen Gastrocnemius desselben Frosches gleich groß sei. Zwischen der 7. bis 2I. Stunde ist die direkte Erregbarkeit des ischämischen Muskels erhöht, er reagiert noch auf Ströme, die an dem normalen Gastrocnemius keine Kontraktionen mehr auslösten. Nach der 21. Stunde kehrten sich die Verhältnisse allmählich um. 42 Stunden nach Ligatur war die Muskulatur für kräftigen Strom noch sehr gut erregbar, wenn auch der Muskel nunmehr bei der tetanisierenden Reizung rascher zu ermüden schien.

Wir konnten in keinem der vielen von uns beobachteten Fälle eine Steigerung der Muskelerregbarkeit feststellen; dieselbe ging vielmehr nach Eintritt der Ischämie fast spontan und derart rapid zurück, daß im Durchschnitt schon nach I 5 Minuten ein deutlicher Unterschied gegenüber dem elektrischen Verhalten der gesunden Extremität nachweisbar war. $2-2^{1 / 2}$ Stunde später sind Kontraktionen bei mittelstarken Strömen noch eben auslösbar; nach 3-4 Stunden erfolgt gewöhnlich auf eine maximale Reizung nur noch eine minimale Zuckung. Kurz hinterher war fast stets die ischämische Unterschenkelmuskulatur für den direkt applizierten faradischen Strom unerregbar; in einem Falle war 
dieser Zustand schon nach 3 Stunden, in einem anderen erst $61 / 2$ Stunde nach Umschnürung manifest.

Thoma löste die Ligatur des Oberschenkels in der Regel nach 35-40 Stunden. Wir ließen dieselbe in zwei Fällen 24 Stunden liegen; erzielten damit eine stark progrediente feuchte Gangrän des peripheren Extremitätenabschnittes; in allen anderen Fällen gaben wir die Zirkulation nach 7 stündiger Konstriktion wieder frei; diese Zeit genügte, um, wie auf Seite 338 erwähnt, die Unterschenkelmuskulatur totenstarr zu machen - ein Effekt, der schon seine Würdigung gefunden hat. Diese Zirkulationsunterbrechung war aber auch intensiv genug, um im Bereiche der Ligaturebene - dem Orte des direkten Muskelfaserinsultes eine ausgedehnte diskoide Zerklüftung einzuleiten, die dann nach Wiedereröffnung der Zirkulation und sekundärer Gewebsdurchtränkung den Charakter einer wachsartigen hyalinen Muskelfaserdegeneration annahm, die der bei Typhus abdominalis beobachteten als gleichwertig zu betrachten, experimentell von uns er. strebt war. Die Folgen dieser 7 stündigen Ischämie waren wir fassen damit bisher schon erwähnte Momente noch einmal zusammen -- aber auch schließlich für die Unterschenkelmuskulatur überhaupt eingreifend genug, um bei Kombinierung mit einem neuen, unten zu beschreibenden Momente einen besonderen Effekt, die ischämische Kontraktur, zu erzielen.

Über die nach Lösung der Ligatur im Bereich der ganzen Extremität auftretenden Veränderungen haben wir schon berichtet; wir fügen noch hinzu, daß wir in fast allen Fällen in wenigen Minuten die mitunter auffallend schnelle Entwicklung petechialer Blutungen verfolgen konnten; ein Beweis für die gleichfalls durch die Ischämie verursachte starke Alteration der Gefäßwände; besonders interessant war die an der glatt rasierten Extremität weißer Kaninchen mehrfach gemachte Beobachtung, daß die nach Wiedereröffnung der Zirkulation auftretende reaktive hyperämische Rötung konstant $\mathrm{I}-\mathrm{I}, 5 \mathrm{~cm}$ oberhalb der Ligaturfurche, nicht in der Höhe derselben, proximalwärts abschloß; ein Beleg für die Annahme, daß durch die tiefgreifende Massenligatur auch noch das proximalwärts gelegene Gewebe in einer gewissen Ausdehnung außer Zirkulation gesetzt wurde. Legte man durch die Oberschenkelmuskulatur des nach 7 Stunden 
abgetöteten Tieres einen die Ligaturfurche durchgreifenden Längsschnitt, dann war die als ca. 3-4 $\mathrm{mm}$ breiter grau-gelber Streifen imponierende Zone des direkten Umschnürungsdruckes nach oben und unten von einem je $4-5 \mathrm{~mm}$ breiten dunkelroten, von stecknadelkopfgroßen Blutherden durchsetzten, tief hyperämischen Saume flankiert. Die schmale graue Linie im Bereiche der mittleren Zone, die Thoma beobachtete und mit der Stelle des stärksten Druckes identifizierte, konnte ich in meinen Präparaten keinmal nachweisen.

Bei mikroskopischer Untersuchung dieser Längsschnitte fand sich konstant folgendes:

Die Muskelfasern sind im Bereich des graugelben Streifens hochgradig verschmälert, oft derart, daß die charakteristische Zeichnung derselben überhaupt nicht mehr erkannt werden kann; sie zeigen im großen und ganzen dieselben strukturellen Veränderungen, die oben schon bei Besprechung der Zungenligierung kurz erwähnt, auch von Thoma bei vorstehenden Versuchen wieder nachgewiesen wurden. Die Querstreifung ist allgemein stark verwischt, oft eine extreme Dehiszenz der Bowmanschen Discs innerhalb der intakt gebliebenen Sarkolemmaschläuche festzustellen. Die Faserkerne erscheinen gleichfalls durchweg stark verschmälert, in ihrer Färbefähigkeit nicht sonderlich alteriert; am meisten interessierte auch hier wieder die Beobachtung, daß im Bereiche dieses Druckgebietes eine Faserveränderung im Bilde der oben beschriebenen Zerklüftung nicht einmal angedeutet war. Wenn auch nur in vereinzelten Fällen eine Kontinuitätstrennung beobachtet wurde, dann zeigten gleichwohl die Faserenden keine maximal kontrahierten Wülste; das reaktiv-funktionelle Verhalten der Muskelfasern ist somit im Bereiche dieser Druckzone wie eliminiert, man möchte überhaupt von einem partiellen Fasertode sprcchen, wenn nur die in gleichem Maße insultierten Faserkerne mit ihrer ursprünglichen Form gleichfalls auch ihre vitalen Eigenschaften voll eingebüßt hätten; in Wirklichkeit aber zeigen dieselben gerade in dieser Hinsicht eine auffallende Indolenz. Thom a findet wohl mit der Annahme eines paretischen Faserzustandes den Kern der Sache. Die periphere hyperämische Zone setzte sich in der Regel mikroskopisch in der Form maximal kontrahierter Wülste charakteristisch gegen das eben beschriebene Gebiet ab. Thoma glaubt annehmen zu dürfen, dab diese Wülste die Grenze bezeichnen, bis zu welcher der Druck der Ligatur die Kontinuität der Muskelfasern in erheblichem Grade geschädigt habe. An diese Kontraktionswülste schließt sich distalwärts die oft stärker, oft schwächer ausgeprägte und verschieden weit reichende segmentäre und diskoide Zerklüftung. Die Muskelfaserkerne erscheinen morphologisch kaum von normalen Kernen unterschieden. 
Die 7 stündige Ischämie hat auch auf den ersten Blick keine mikroskopisch sichtbare Veränderung der Muskelfasern und Faserkerne des Unterschenkels zur Folge gehabt. Die Querstreifung ist infolge der Faserstarre wohl in zahlreichen Muskelfasern etwas enger geworden. Bei Serienschnittuntersuchung des M. gastrocnemius und extensor digitorum communis wird man aber bald eines Besseren belehrt; wenn auch nicht allzu zahlreich, so fallen doch immer wieder einzelne Fasern auf, die eine gewisse Strecke lang nahezu dieselben Formveränderungen zeigen, wie sie oben beschrieben wurden. - Auch im Bereiche des proximalen, schmalen, hyperämischen Saumes sind die Muskelfasern in wachsartig glänzende, kontrahierte Segmente zerklüftet, zwischen denen diskoide, fein- und grobkörnige Massen in verschieden großen Mengen nachweisbar sind; daneben sieht man aber schon Faserbilder, die den bei Typhus abdominalis beobachteten außerordentlich nahe zu stehen scheinen; man hat darnach anzunehmen, daß die Blut- und Lymphzirkulation in diesem Gebiete nicht ganz erloschen war; die Ernährungsstörung war wohl groß genug, um beim Zusammentreffen mit der direkten Faserläsion den bekannten Effekt zu zeitigen. Die, wenn auch nur geringe Saftdurchströmung genügte dann aber auch schon, um die wachsglänzenden Segmente und diskoiden Massen innerhalb der Sarkolemmschläuche zur Aufquellung zu bringen, oft mit Einschluß der maximal kontrahierten Wülste, die korrespondierend den Wülsten der distalen Zone, auch für den proximal hyperämischen Saum ursprünglich wohl die charakteristischen Grenzsteine darstellten. Wir fügen noch hinzu, daß in den hyperämischen Säumen neben starker intravaskulärer Blutanschoppung zahlreiche freie Gewebsblutungen zu erkennen waren.

Über die der Lösung der Ligatur folgenden, oft außerordentlich starken makroskopisch sichtbaren reaktiven Erscheinungen haben wir schon zum Teil berichtet; wir ergänzen diese Beobachtungen noch dahin, daß, tötete man die Versuchstiere nach 2 mal 24 Stunden oder noch später, fast ausnahmslos eine ausgedehnte Thrombosierung der Muskelvenen aufgedeckt wurde; die Thromben ließen sich als lange Fäden aus den größeren tiefen Gefäßen mit leichter Mühe extrahieren. Der N. ischiadicus erwies sich oberhalb der Ligatur makroskopisch als intakt, im 
Bereiche der Ligaturfurche fast ausnahmslos als stark blutig tingiert, kontundiert und brüchig; der periphere Teil (N.tibialis posticus) war in einigen Fällen von petechialen Blutungen übersät und ausnahmslos ödematös geschwollen; daß an ähnliche Alteration sich schließlich völlige Degeneration der peripheren motorischen Nerven anschließen kann, bedarf keiner besonderen Betonung.

Abgesehen davon, daß wir manche Tiere nach Lösung der Ligatur zwecks Studium des schließlichen Regenerationseffektes und anderer Vorgänge für längere Zeit frei gaben, töteten wir in Verfolgung der weiteren Entwicklung des degenerativen Faserprozesses andere in ganz bestimmten Zeitabständen. 2 mal 24 Stunden zeigte die Oberschenkelmuskulatur im ursprünglichen Ligaturbereiche nahezu die gleichen, nur charakteristischer in ihren Farbunterschieden vortretenden Säume.

Der periphere Saum war gewöhnlich stärker hyperämisch; in dem peripheren Muskelabschnitt des Oberschenkels sah man häufig, in den Unterschenkelmuskeln nahezu konstant größere oder kleinere Blutextravasate. Die mikroskopische Untersuchung des frischen Zupf- und gefärbten Schnittpräparates ergab ganz prägnante Resultate.

Die proximale hyperämische Zone und der nächstbenachbarte Teil der scheinbar intakt gebliebenen Oberschenkelmuskulatur bilden geradezu eine $F$ undgrube der schönsten Degenerationsformen; von äquivalenten, wachsglänzenden, kontrahierten Fasersegmenten, von scharfumrissenen Kontraktionswülsten überhaupt ist keine Spur mehr nachweisbar. An deren Stelle sieht man Sarkolemmaschläuche in weiter Ausdehnung von grobkörnigen diskoiden Massen angefüllt. Andere erhalten durch stärkere Prominenz der gequollenen, total homogen gewordenen, strukturlosen, ursprünglichen Kontraktionswülste - die wieder durch fein gekörnte, von der stark kollabierten Sarkolemmahülle überzogene Massen voneinander geschieden sind - ein mehr rosenkranzähnliches Aussehen; in wieder anderen Sarkolemmahüllen haben sich die diskoiden Massen scheibenförmig angeordnet; daneben sieht man Sarkolemmaschläuche mit homogenen, polymorphen Schollen, die die Hämatoxylinfärbung auffallend stark annehmen; diese Schollen zeigen fast ausnahmslos größere oder kleinere Vakuolen. Item: Die ursprüngliche Struktur der Muskelfasern ist im großen und ganzen nicht mehr im entferntesten zu erkennen; die Faserkerne sind, soweit solche in diesem Bereiche überhaupt noch vorhanden, größtenteils ebenfalls total zerfallen; von den Kernfragmenten sind 
die zahlreich zerstreuten, eingewanderten Lèkocyten wohl zu trennen. Dem ursprünglichen Kompressionsgebiete sind proximal- und distalwärts durch Hämatoxylin schwarzblau gefärbte Wälle vorgelagert: das sind Ansammlungen von Leukocyten, scheinbar intakt gebliebenen Faserkernen und Kernfragmenten. Die Muskelfasern dieses Gebietes erscheinen, soweit sie als solche überhaupt noch erkennbar sind, offenbar durch Flüssigkeitsaufnahme etwas verbreitert und nahezu kernfrei; die Sarkolemmaschläuche, im großen und ganzen auffallend gut erhalten geblieben, sind ausnahmslos von fein- und grobkörnigen diskoiden Massen angefüllt; ein einheitlicheres und geschlosseneres Bild ist in keiner anderen Zone mehr zu finden. Die maximal kontrahierten Wülste und Segmente des peripheren stärker hyperämischen Saumes haben eine extreme Breitenzunahme erfahren; die Bezeichnung „Wachskerzen" drängt sich spontan auf bei Betrachtung dieser glänzenden, scharf konturierten, scheinbar homogenen Fasergebilde; bei Untersuchung mit starken Systemen ist aber gerade in diesen Zerfallstypen oft genug noch eine zarte extrem-enge Querstreifung nachzuweisen; zwischen den Begrenzungsflächen dieser Segmente sind hier und da von Kernfragmenten durchmischte diskoide Massen gewöhnlich in geringer Menge ausgebreitet. Die proximalen, in stark ausladende Kontraktionswülste auslaufenden Endstücke dieser größtenteils auch kernfreien Faserteile sind in den oben besprochenen Zellund Kernhaufen eingebettet. Dieser Typ beherrscht keineswegs das ganze Gesichtsfeld, vielmehr sieht man immer wieder Faserhüllen mit den oben beschriebenen polymorphen Zerfallsprodukten; das Ausdehnungsgebiet beider Degenerationsformen ist weiter distalwärts weniger scharf begrenzt, entsprechend der jeweiligen Fernwirkung der Faserläsion. Die nächstfolgenden Muskelfasern bzw. Faserteile, die nicht mehr von der posttraumatischen Kontraktionswelle getroffen wurden, zeigen Veränderungen, die sich in nichts von den Zerfallsbildern unterscheiden, die die mikroskopischen Schnitte nahezu sämtlicher Unterschenkelmuskeln beherrschen, übrigens oben auch schon wiedergegeben wurden. Die Fasern haben die Tendenz, in größeren oder kleineren Abständen in der Richtung der Bowmans Discs partiell oder total auseinander zu weichen. Die Querstreifung bleibt immer deutlich, wenn auch häufig durch Risse innerhalb der kontraktilen Substanz und Verschiebung der Faserfibrillen verzerrt. Die mitunter zu beobachtende, durch die Myosingerinnung fixierte, starke Diastase der Querscheiben bei intakter Sarkolemmahülle ist auf intensivere Zugbeanspruchung zurückzuführen: Die passive Überdehnung war schließlich stärker als die Faserkontraktilität; sie überdauerte auch endlich die Wirkung der durch die Ischämie bedingten Starre, die sich somit eben in der einfachen Fixierung dieses Faserzustandes (Myosingerinnung ohne Kontraktion) erschöpfte. Diese Überdehnung war in anderen Fällen wieder groß genug, um schließlich 
die Kontinuität der Muskelfasern zu sprengen, damit eine Hauptbedingung für das Zustandekommen des Faserzerfalls zu schaffen, der in seinen ersten Stadien oben schon beschrieben wurde und nach Wiedereröffnung der Blut- und Lymphzirkulation in vorliegendem Falle Formen angenommen hatte, die gleichfalls mit denen des proximalen hyperämischen Saumes identisch waren. Der Kernschwund ist auch im Bereiche der Unterschenkelmuskeln manifest; überall erblickt man Konglomerate von Kernsplittern und Wanderzellen, die schon in großen Mengen das degenerierte Fasermaterial durchsetzen; auch große Mengen von Kapillarkernen sind der siebenstündigen Ischämie zum Opfer gefallen. Neben diesen Degenerationsprodukten sieht man nicht gerade vereinzelt überall verstreut normal konturierte, auch strukturell scheinbar intakt gebliebene Faserkerne. An diese Kerne, die die $\mathrm{CO}_{2}$-Intoxikation überstanden haben, knüpft sich wie früher schon betont - die eigentliche Faserregeneration; ob man es Zufall nennen soll oder nicht - auffallend erscheint es doch, da $B$ man, wenn auch nur in vereinzelten Fällen Muskelfasern zu Gesicht bekommt, deren Kerne trotz oft starker Verwerfung der eigentlichen Faserstruktur, intakt und regenerationsfähig geblieben erscheinen.

3 Kaninchen wurden 8 mal 24 Stunden nach Lösung der 9 stündigen Massenligatur abgetötet; makroskopisch zeigten die durch das Ligaturgebiet gelegten Längsschnitte nahezu dieselben, farbig nur noch schärfer gegeneinander abgesetzten Zonen; zwischen dunkelroten Säumen eine ockergelbe, scheinbar homogene Schicht. Die mikroskopische Untersuchung gerade dieser Präparate hat uns schon früher, bei Untersuchung der Faserregeneration interessiert; für vorliegendes Kapitel erheischte die weitere Verfolgung der Degenerationsformen besondere Aufmerksamkeit.

In allen drei Zonen ist die vorher geschilderte Degenerationsform (diskoide Zerklüftung), wenn überhaupt vorhanden, so doch nur noch in Spuren nachweisbar. In der gelben Schicht sieht man hier und da kleinste, teilweise noch quergestreifte, teilweise homogen erscheinende Faserfragmente mitten in einem Chaos von Kernen, Kernketten, sowie spindel- und sternförmigen Zellen mit meistenteils ovalen, bläschenförmigen Kernen und gewöhnlich zwei Kernkörperchen; eine gleichfalls außerordentlich starke Kernproliferation ist im Bereiche des proximalen Saumes nachweisbar. Neben den sogenannten Muskelzellschläuchen sieht man mitunter völlig leere oder nur noch von geringen feinkörnigen Massen partiell gefüllte, gleichwohl oft geradezu erstaunlich gut erhalten gebliebene Sarkolemmahüllen; vor allem aber ist das Gesichtsfeld beherrscht von eigenartigen, direkt aufdringlichen Faserbildern; mehr oder weniger gut erhaltene Sarko- 
lemmaschläuche umschließen oft größere oder kleinere Kernhaufen; diese haben sich wieder dicht um größere oder kleinere, auffallend transparente, gänzlich homogene und säurefeste, klumpige Massen gruppiert, die eine auffallende Affinität zu der Hämatoxylinfärbung zeigen und einen dunkelblauen Ton angenommen haben; je näher man der gelben Zone kommt, um so reichlicher sind diese Degenerationstypen vertreten. Am ehesten kann man noch an den mehr peripher, in Wirklichkeit proximal gelegenen Typen das eigentliche Wesen dieser Faserprodukte, die ich im ersten Augenblicke beinahe als Kalkkonkremente gedeutet hätte, studieren: dieselben sind nichts anderes als die Residuen der diskoiden Zerkluiftung, die in den vorigen Präparaten in ausgiebigstem Maße gerade in diesem Gebiete vertreten war. Es handelte sich $\mathrm{m}$. E. um wachsartig veränderte Fasern, deren Kerne zum Teil noch lebensfähig geblieben waren; auf eine Proliferation gerade dieser Kerne - nicht auf Leukocyteninvasion sind die starken Kernanreicherungen innerhalb der Sarkolemmahüllen zurückzuführen, die mitunter dem Bilde des Muskelzellenschlauches gleichkommt; mit diesen Proliferationsvorgängen ging eine entsprechend ausgedehnte Resorption der wachsartig glänzenden Massen einher. Es hat nun den Anschein, als ob die fein- und grobkörnigen diskoiden Massen in erster Linie dieser Resorption anheimgefallen wären und nur die maximal kontrahierten Wülste und Ringe auch nach Aufquellung derselben gegenüber eine größere Resistenz zeigten, denn $\mathrm{m}$. E. besteht ein direkter morphologischer Zusammenhang zwischen diesen Kontraktionsprodukten und den von feinsten RiBlinien durchzogenen Klumpen; in bezug auf Größe, Lagerung und Konturierung herrscht völlige Übereinstimmung; Querstreifung ist nicht zu erkennen. Die Beobachtung einer besonderen Affinität dieser Klumpen zum Hämatoxylin halte ich auch deshalb für nicht besonders bemerkenswert, weil auch schon die diskoiden Massen vor der Quellung eine viel intensivere Färbung annehmen als die normalen Muskelfasern; die eigentliche Ursache und Bedeutung dieses Phänomens, die Frage, ob demselben ein physikalischer oder chemischer Vorgang zugrunde liegt, habe ich nicht weiter untersucht.

Ein ganz anderes Bild bietet die periphere Zone: Die diskoiden zerklüfteten Fasern sind mitsamt ihren Hüllen verschwunden; nahezu völlig unverändert blieben die der gelben Zone zugekehrten, mit ihren Endwülsten in Kern- und Zellmassen eingetauchten wachskerzenähnlichen, stark glänzenden, segmentierten Fasern, deren feinste Querstreifung immer noch deutlich erkennbar ist; weiter distalwärts besteht universelle Faserfragmentierung, bei scharf gezeichneter, normal weiter, hier und da überdehnter Querstreifung aber leichter Reduzierung der Faserbreite. Aus den Faserfragmenten sowie den Interstitien sind die Zellen und Kerne so gut wie ausgewaschen; ob die wenigen überlebenden Kerne überhaupt noch proliferationsfähig sind, 
erscheint wenig wahrscheinlich, ihrer Konfiguration nach können sie nur eben noch identifiziert werden; größere Zellen- und Kernanhäufungen findet man nur in den oberflächlichsten Faserschichten; von den Zellmassen, die von der gelben Zone aus die Endstücke der wachskerzenähnlichen Fasersegmente umwuchern, haben wir schon bèrichtet; dieselben scheinen in der Hauptsache aus phagocytären Leukocyten zu bestehen, die, wie man hier und da schon beobachten kann, ihrer Aufgabe, die Resorption dieser toten Fasergebilde herbeizuführen, in vollem Umfange gerecht werden; man sieht dieselben gewöhnlich als Riesenzellen um Partikelchen der kontraktilen Substanz gelagert, noch innerhalb der Sarkolemmahülle; in anderen Fällen sind In der kontraktilen Substanz Vakuolen nachweisbar. Es gelang uns mehrfach, in der Umgebung solcher Fasern Zellkonglomerate nachzuweisen, die der Größe nach genau in diese Lücken hineinpaßten; in wieder anderen Fasersegmenten erscheinen die Randpartien mitunter wie ausgestanzt: Die Sarkolemmahülle war an ganz zirkumskripter Stelle von Phagocyten eingeschmolzen - letzteren wurde dadurch das Gebiet der kontraktilen Substanz zu weiterer lakunärer Ausbreitung wieder eröffnet.

Nicht ohne Absicht habe ich die an das eigentliche Kompressionsgebiet grenzenden Zonen in allen Fällen getrennt besprochen. Der Unterschied in den degenerativen und regenerativen Vorgängen im Bereich der durch Trauma und Ischämie geschädigten Muskelfasern ist nicht gerade prinzipiell, aber immer zur kurzen Skizzierung interessant genug.

Von einer ausgedehnten diskoiden Zerklüftung und der grotesken Veränderung der Zerklüftungsprodukte, die in vollem Umfange erst nach Wiedereröffnung der Zirkulation in Erscheinung treten, von einem später dann überall, im ganzen Bereiche der proximalen Zone einsetzenden Regenerationsbestreben ist in der peripheren Zone nur wenig zu beobachten; statt dessen imponieren und persistieren die kontrahierten, stark wachsglänzenden Segmente, deren am ehesten auffallende Veränderung nach Eröffnung der Blut- und Lymphzirkulation in einer Verbreiterung des Querschnitts und zunehmender Dichte der Querstreifung sowie in einer stärkeren Fragmentierung besteht. Wahrscheinlich wurde der auf die Querschnittsläsion folgende Kontraktionszustand durch eine spontan einsetzende Myosingerinnung so schnell festgehalten, daß eine weitere Zerklüftung, die nach unseren früheren Ausführungen immer noch einen gewissen Grad von Lebenstätigkeit der Faser zur Voraussetzung hat, nicht mehr aufkommen konnte. 
Daß mit Eintritt dieses Zustandes der Tod der Faser im Bereich des Läsionsgebietes bzw. in Ausdehnung der Kontraktionswelle verbunden war, beweist die schließliche Resorption der Faserkerne und kontraktilen Substanz. Die nach Kontraktion unserer Vermutung nach spontan einsetzende Myosingerinnung ist $\mathrm{u} . \mathrm{E}$. auf die Wirkung zweier Momente, des Traumas und der Ischämie, zurückzuführen; es ist eine bekannte Tatsache, daß die Starre an den Muskeln im allgemeinen am Orte der Läsion zunächst eintritt; darnach müßte - so könnte man deduzieren — im Anschlusse an die Muskelläsion, die gleich nach Eintritt des Todes gesetzt würde, nur diese Faserveränderung zu erwarten sein; in Wirklichkeit ist aber, wie oben mitgeteilt, auch postmortal auf experimentellem Wege eine diskoide Zerklüftung zu erzielen, freilich - und diese Feststellung stützt unsere Behauptung sehr selter an den trocken aufbewahrten, vorwiegend an den in physiologischer Kochsalzlösung konservierten Muskelpräparaten. Thoma gelangt zu der Vermutung, daß ein größerer Wassergehalt des Sarkolemminhalts den diskoiden Zerfall begünstige, letztere Beobachtungen sprächen dafür; damit — so fährt er bei Beurteilung auch seinerseits gemachter ähnlicher Beobachtungen fort - sei es vielleicht zu erklären, daß der diskoide Zerfall in verletzten, aber noch blutdurchströmten Muskelgebieten reichlicher aufzutreten pflege, als in vollkommen ischämischen, in gleicher Weise verletzten Muskelmassen; weil — so fügen wir hinzu - im ersten Falle vor allem eine vorzeitige Myosingerinnung hintangehalten und längere Lebensdauer garantiert wurde, ein Umstand, der einer eventuellen Ausbreitung der diskoiden Faserzerklüftung entgegenkommt.

Wir berichteten schon von dem nahezu totalen Kern- und Kernsplitterschwunde im Bereiche des an die letztbeschriebene Zone angrenzenden, in die Sehne übergehenden Muskelgewebes. Bei zwei Versuchstieren konnte derselbe Befund auch in den zentralen Schichten der Unterschenkelmuskulatur erhoben werden, und zwar handelte es sich in dem einen Falle um den M. gastrocnemius, in dem anderen um den M. extensor digitorum communis; diese Muskelpartien boten auch gleichzeitig das Bild ausgedehnter Faserfragmentierung; die einzelnen Fragmente zeigten durchweg noch außerordentlich scharfe Querstreifung; daneben 
sah man nicht gerade vereinzelt besterhaltene Typen der wachsartigen Faserveränderung, deren Genese (Selbstzerreißung plus Zirkulationsstörung) früher bereits gewürdigt wurde, aber auch diese kernentblößt. - Auf der Suche nach ätiologischen Faktoren fanden wir in den zugehörigen Protokollen den Vermerk', daß bei der Autopsie gerade in diesen beiden Fällen eine stärkere Thrombosierung der Venen festgestellt wurde, die, wie dann im gefärbten Schnittpräparate deutlich nachzuweisen war, auch auf die Gefäßäste dieser Muskeln sich ausgebreitet hatte. Unter diesen Umständen glaubten wir annehmen zu dürfen, daß den während der Ligaturperiode lebenskräftig gebliebenen Kernen nach Lösung der Umschnürung infolge einer durch die Thrombosierung bedingten Zirkulationsverzögerung bzw. Stasis nicht die O-Menge zugeführt wurde, die zur Auffrischung und Weiterentwicklung unbedingt nötig war. Unter der fortdauernden $\mathrm{CO}_{2}$-Intoxikation verfielen sie dann schließlich der Nekrose und der zersetzenden und auflösenden Wirkung des Lymphstromes.

Das Zellengewirr im Bereiche der oberflächlichen Schichten dieser Muskeln spricht von einem daselbst noch waltenden, lebhaften Lebensprozeß. Von Kernsplittern ist hier ebensowenig zu sehen wie in den mikroskopischen Schnittbildern anderer Muskeln; lebhafteste Proliferationstendenz zeigen vor allem die Muskelfaserkerne. Die Nekroseherde sind durch Leukocytenhaufen, die von dem Proliferationsgebiete vorgeschoben wurden, augenfällig von demselben isoliert. Interessant ist ein Vergleich der Faserstücke beider Regionen; beiden gemeinsam ist die starke Diastase, verschieden aber die die Faser trennende $Z$ wischensubstanz, d. i. im Bereich der totalen Fasernekrose: eine indifferente, von zellulären oder überhaupt korpuskulären Elementen freie Flüssigkeit (Ödem), in dem Proliferationsgebiete ein außerordentlich zellreiches, von feinsten Fasern durchzogenes Gewebe; weiter auffallend ist der Unterschied in der Faserstruktur: in letzterem Falle ist die Fibrillenzeichnung vorherrschend, im anderen ausschließlich die charakteristische Querstreifung.

Wenn einmal der Satz zu Recht besteht, daß die hyalinen Veränderungen der Muskelfasern der kombinierten Wirkung einer Faserläsion und Zirkulationsstörung zuzuschreiben ist, dann wird man beispielsweise auch in der Umgebung von Knochenfrakturen entsprechende Bilder $z u$ erwarten haben: die Untersuchungsresultate bestätigten die Annahme. Der experimentelle Erfolg war aber auch freilich immer nur dann positiv, wenn eine Faser- 
läsion in Wirklichkeit zustande gekommen war. Das durch die Knochenspießung erzeugte Muskelhämatom ruft wohl Zirkulationsstörungen hervor, damit allein aber noch nicht diese Faserveränderungen; davon habe ich mich in entsprechenden Experimenten stets überzeugen können.

In allen den bisher beschriebenen Fällen war die partielle und totale Kontinuitätstrennung der Muskelfasern der direkte oder indirekte (Selbstzerreißung infolge passiver Überdehnung!) Effekt einer von außen einwirkenden Gewalt. - Bei den Versuchen, auch auf direktem experimentellem Wege der Auffassung Thomas, daß die sogenannte wachsartige Veränderung der Muskulatur bei Typhus abdominalis auf eine bei aktiven Bewegungen eintretende Selbstzerreißung unterernährter Muskelfasern zurückzuführen sei, Boden zu gewinnen, fand ich in der Terpentinölwirkung einen wohl geeigneten Entstehungsmodus. Das hauptsächlichst prädisponierende Moment, das durch die direkt toxische Wirkung dieses Agens geschaffen wird, ist m. E. die Herabsetzung der Widerstandsfähigkeit der Muskelfaser; hinzu kommt dann die durch das hochgradig entzündliche Gewebsödem und die sekundären Zirkulationsstörungen bedingte Insuffizienz des Gasaustausches, Störungen, die schon a priori eine Selbstzerreißung der Muskelfaser bei maximaler, aktiver und passiver funktioneller Inanspruchnahme zum mindesten wahrscheinlich machten, und auch in Wirklichkeit, wie durch die Versuche einwandfrei festgelegt werden konnte, im Verein mit diesem Momente ein über alles Erwarten günstiges Resultat zeitigten. Zur Illustration der Versuchsanordnung und reaktiven Erscheinungen lasse ich zwei Protokolle folgen:

F a 11 I. In den Unterschenkel eines ausgewachsenen Kaninchens (distale Muskelsehnengrenze) wurden $2 \mathrm{ccm}$ sterilen Terpentinöls in jiziert; das Tier wird dann sofort in einen engen Kasten gesetzt, um aktive Bewegungen der hinteren Extremität nach Möglichkeit zu beschränken; durch eine ötfnung in der vorderen Kastenwand, in die das Tier seinen Kopf gerade noch einzwängen kann, wird demselben die Nahrung gereicht; die kranke hintere Extremität wird durch Verschiebung der zugehörigen Seitenwand des Kastens der Inspektion und genaueren Untersuchung zugänglich gemacht. - Schon in den ersten Stunden nach der Injektion entwickelt sich ein außerordentlich starkes, über Fuß, Unter- und Oberschenkel sich ausdehnendes Ödem; 
auffallend ist die früh eintretende, allem Anscheine nach starke Druckempfindlichkeit sämtlicher, von dem Gewebsödem eingeschlossener Extremitätenmuskeln; bei mittelkräftiger Palpation schrie das Tier fast jedesmal laut auf. Ungefähr drei Wochen nach Injektion war das ödem abgeklungen, die Muskulatur derb-fest, sie reagierte prompt auf mittelstarken faradischen Strom bei direkter und indirekter Reizung. Unterschenkel und $\mathrm{FuB}$ standen in 45 Grad Flexionsstellung kontrakt; sämtliche Zehen waren in Krallenstellung eingeschlagen; Haut-Weichteil-Nekrosen fehlten, insbesondere war die Injektionsstelle frei von makroskopisch nachweisbaren Veränderungen. Acht Wochen später ist die Muskulatur immer noch von der derben Konsistenz, in toto atrophiert; die Kontrakturstellung von Unterschenkel, Fuß und Zehen manifest; die passiven Bewegungen werden zu tunlichster Vermeidung von Faserrissen äußerst behutsam ausgeführt. Die faradische Untersuchung ergibt immer noch mittlere Werte. Zwölf Wochen nach Injektion wurde ein pfenniggroßes Dekubitalgeschwür über der Ferse festgestellt; im übrigen Status idem; das Tier wurde dann getötet. Die Obduktion ergab: Freie Verschieblichkeit der Haut; ein Eiterherd im Unterhautzellgewebe nicht vorhanden; die Muskulatur der nahezu total kontrakturierten Extremitätenabschnitte war fahlgelb-braun gefärbt, von eigenartig glänzenden, schmalen Gewebsstreifen durchsetzt, knirschend-derb bei der Durchschneidung; die großen Nervenstämme erscheinen im ganzen verschmälert, ohne den typischen Silberglanz. Bei der mikroskopischen Untersuchung fand sich neben nahezu normaler Strukturierung deutliche Verschmälerung der Muskelfasern; die Faserkerne erschienen infolge stärkeren Zusammenrückens vermehrt; einzelne Fasern waren parenchymatös getrübt; in anderen war fettige Degeneration (Sudanfärbung) nachweisbar; wachsartige Veränderung wurde trotz eingehender Untersuchung nur in wenigen Fasern des $\mathrm{M}$. extensor digitorum, und zwar im Bereiche der proximalen Sehnenmuskelgrenze gefunden; in diesem Falle liegt das eine ursächliche Moment in der Faserzerreißung; letztere ist wieder der Effekt passiver Überdehnung - die notwendige Folge des manuellen Redressements, das bei den letzten Dehnungsversuchen etwas forcierter betrieben wurde. Der Umstand, daß wir die Präparate sofort nach dem Tode des Tieres in Formalin legten, spricht gegen die Annahme einer postmortalen Entstehung dieses Zerfallstypus. Besondere Beachtung verdient die Feststellung, daß die oben beschriebenen glänzenden Gewebsstreifen ausgedehnten Bindegewebszügen entsprechen, die in ein weit verzweigtes Netz feinster Stränge auslaufen. Diese Bindegewebsstränge, an Umfang dem Perimysium internum der Muskelfasern stark überlegen, umflechten die einzelnen Fasern oder Fasergrupppen; dieselben erscheinen mitunter von diesen Gewebsmassen wie stark konstringiert.

F all 2. Das Tier wird nach der Injektion sofort in Freiheit 
gesetzt; auch in diesem Falle entwickelte sich innerhalb zwei Stunden ein starkes, über FuB, Unter- und Oberschenkel sich ausbreitendes heißes Ödem, verbunden mit zunehmender Druckempfindlichkeit der Muskulatur; am nächstfolgenden Tage hüpft das Tier, die stark geschwollene Extremität hinter sich herschleppend, munter umher; die selbe wird kräftig dreimal täglich je $1 / 2$ Stunde lang faradisiert; am fünften Tage nach der Einspritzung ist die Schwellung schon stark zurückgegangen; die Muskulatur aber immer noch sehr druckschmerzhaft. Von jetzt ab wird das Tier täglich gründlich bewegt, längere Zeit im Stall herumgejagt, dazu das kranke, wieder leicht kontrakturierte Bein passiv gestreckt und dreimal täglich kräftig faradisiert. Nach drei Wochen ist die Kontrakturstellung geschwunden; die einzelnen Extremitätenabschnitte funktionieren aktiv nahezu normal; sie reagieren prompt auf schwachen faradischen Strom bei direkter und indirekter Reizung. Acht Wochen später ist die Extremität aktiv wieder frei beweglich, aber in toto atrophiert. Die Haut ist verschieblich; eine linsengroße, frische Granulation in der Umgebung der Infektionsstelle. Die Muskeln sind noch leicht druckschmerzhaft, etwas stärker konsistent. Zwölf Wochen nach Injektion ist außer leichter Atrophie eine merkliche pathologische Veränderung makroskopisch und palpatorisch nicht mehr nachweisbar. Das Tier wird getötet. Obduktionsergebnis : Die Haut ist überall frei verschieblich; direkte subkutan oder tiefer gelegene Abszeßherde fehlen; in der Kniekehle liegt ein stark entzïndlich geschwollener Lymphknoten; die atrophischen und infolge starken Schwundes ihrer Bindegewebslager leicht zu isolierenden Muskeln haben eine blaßrote Farbe; sie sind weich und elastisch. Mikroskopisch ist eine mittelgroße Dehiszenz einzelner Fasergruppen nachweisbar; hyperplastische Bindegewebszüge sind nicht vorhanden; neben den etwas verschmälerten Muskelfasern sieht man überaus zahlreiche und mannigfaltige Regenerationsbilder und über Erwarten schöne Typen sämtlicher Phasen der wachsartigen Faserveränderungen.

Außer diesem positiven Ergebnisse haben wir noch weitere bemerkenswerte Beobachtungen zu notieren, die wohl geeignet sein durften, unsere Studien über die ischämische Myositis und ihre Folgezustände in eine ganz bestimmte Bahn zu lenken.

Auf Seite 3I I, bei Besprechung der Regenerationsvorgänge, brachten wir die definitive Bestimmung der ersten Regenerationsprodukte mit der funktionellen Inanspruchnehme des insultierten Muskels in näheren Zusammenhang. Wir vindizierten derselben eine ganz bestimmte elektive Wirkung im Sinne einer spezifischen Beeinflussung bestimmter Individuen der überreichlich produzierten Muskelzellen. Die Zellen, die dem funktionellen 
Reize sich anzupassen in der Lage sind, erfahren eine weitere, ich möchte sagen muskelspezifische Entwicklung; alle übrigen verfallen der Degeneration oder einer Metaplasie in fixe Bindegewebszellen. Fehlt dieser funktionelle Reiz, dann kommt als Endausgang regeneratorischer Bestrebungen nur die Degeneration oder Metaplasie in Frage. Ich wüßte sonst keine Erklärung für die ausgedehnte Schwielenbildung, wie ich sie in Muskeln im Anschluß an größere oder kleinere Läsionen, die längere Zeit nach Resektion der zugehörigen motorischen Nerven gesetzt wurden, mehrfach nachweisen konnte. Bestreiten will ich nicht, daß außer dem umliegenden, durch den Schnitt lädierten Muskelgewebe, auch noch das interstitielle Bindegewebe, das, wie bekannt, einige Wochen nach Nervenläsion - oft erheblich -hypertrophiert und sich in breiten Zügen zwischen die Muskelfasern schiebt, an der Ausfüllung des künstlich gesetzten Defekts teil hat. Von obigem Gesichtspunkte aus bedarf Fall 2 keines weiteren Kommentars; unsere Auffassung wird gleichsam in ihm repräsentiert.

In Fall I waren die aktiven Bewegungen stark behindert, damit einmal die Zirkulation an und für sich träger geworden. Hinzu kam die aseptische, durch die Terpentinöl-Injektion erzeugte Entzündung und das sekundäre Ödem; die Zirkulationsstörungen und dann die Muskelinsuffizienz genügten, um das Ödem möglichst lange zu lokalisieren. Die Folge dieser Blut-Lymphstasis und des entzündlichen Reizes war die vorhin skizzierte ausgedehnte Bindegewebswucherung und der Effekt der schließlich eintretenden Gewebsschrumpfung: die Kontraktur. Durch das pralle, auch die Muskeln durchsetzende Ödem wurde naturgemäß der Gewebsdruck erhöht, mithin wieder in ganz besonderem Maße die arteriellen und venösen Blutbahnen affiziert, ein Zustand, der durch frühzeitiger einsetzende Muskelbewegungen, wie Fall 2 zeigt, in weiterem Umfange besserungsfähig gewesen wäre. Neben der toxischen Wirkung des Terpentinöls kam somit noch die mangelhafte Nahrungszufuhr, insbesondere aber die durch den insuffizienten Gasaustausch bedingte $\mathrm{CO}_{2}$-Anreicherung als ursächliches Moment für die allgemeine Muskelfaseratrophie in Frage; es ist mit Bestimmtheit anzunehmen, daß mit der Faseratrophie in vielen Fällen eine reguläre Faserdegeneration einherging; an 
diese schlo $B$ sich dann wieder der Regenerationsproze $B$ an, der aber aus den oben beschriebenen Gründen nicht zum Abschluß kommen konnte, vielmehr bald erschöpft war; die regressive Umwandlung der noch primitiven Regenerationsformen war unter diesen Umständen wieder der schließliche Ausgang. Für diese Annahme spricht die starke Reduzierung der Faserzellen sowie die starke, oft herdförmig ausgebreitete Bindegewebsneubildung.

Mit einer kurzen Zusammenstellung andersartiger, in unseren Präparaten beobachteter Degenerationsformen glauben wir der vor Schilderung der sogenannten wachsartigen Verändenung der Muskelfasern gemachten Ansage voll und ganz gerecht zu werden; eine ausführliche Definition der parenchymatösen oder fettigen Faserdegeneration (Seite 366) erübrigt. Besonders schöne Bilder von einfacher Faseratrophie sowie von Atrophie mit mehr oder weniger starker Wucherung von Bindegewebe und Fettgewebe lieferten die Muskeln nach Resektion der zugehörigen motorischen Nerven. Die Verschmälerung der Muskelfasern des ersten Terpentinölversuchs war der Effekt der Inaktivierung. Muskelfasern, die längere Zeit in ein allgemeines Gewebsödem mit einbegriffen waren, zeigten in Längs- und Querschnitten oft ausgedehnte, mit Flüssigkeit gefüllte Vakuolen. Über Faservakuolen ganz anderer Genese wurde schon auf S.362 berichtet; als Fundort beschrieben war die periphere, hyperämische Zone; ganz besonders häufig zeigte sich dieser von Litten als ,röhrenförmige Degeneration“ beschriebene Typus, der mit Recht als Resorptionsvorgang gedeutet wurde, in gangräneszierendem Muskelgewebe. In diesem Falle waren die von einer homogenen fein granulierten Fasersubstanz umschlossenen Hohlräume von Zellen angefüllt, die in ihrer Form gewucherten Muskelfaserzellen wohl ähneln konnten, in Wirklichkeit aber unzweifelhaft als eingewanderte, zu Riesenzellen ausgewachsene Leukocyten $z u$ betrachten sind. Die durch diese Zellen bewirkte Einschmelzung der kontraktilen Substanz war oft derart intensiv, daß man einzelne Fasern zwanglos als Hohlzylinder bezeichnen konnte, deren Wand durch eine hier und da arrodierte Sarkolemmhülle und eine schmale homogene Mantelschicht dargestellt wurde.

(Fortsetzung folgt.) 